\title{
LA INTERMEDIACIÓN DE SEGUROS EN EL CENTRO DE LAS CORRIENTES REFORMADORAS, ESTADO DEL ARTE EN LA UNIÓN EUROPEA Y COLOMBIA*
}

\author{
INSURANCE INTERMEDIATION IN THE MIDDLE OF \\ THE REFORM FORCES. STATE OF THE ART IN THE \\ EUROPEAN UNION AND COLOMBIA
}

\author{
FELIPE TABARES CORTÉS** \\ Fecha de recepción: 30 de abril de 2018 \\ Fecha de aceptación 24 junio de 2018 \\ Disponible en línea: 15 de marzo de 2019
}

Para citar este artículo/To cite this article

Tabares Cortes, Felipe, La intermediación de seguros en el centro de las corrientes reformadoras, estado del arte en la Unión Europea y Colombia, 49 Rev.Ibero-Latinoam.Seguros, 161-215 (2018). https://doi.org/10.11144/Javeriana.ris49.

isce

doi:10.11144/Javeriana.ris49.iscc

Artículo de Reflexión

** Abogado del CSJ de Colombia y de la barra de Francia (Paris), candidato a Doctor, Université Sorbonne-Nouvelle, Especialista en Derecho Médico de la Universidad del Rosario, Maestría en Derecho de Seguros de l'Université Lyon III Jean Moulin, Preparación del Centro de Formación de Abogados de l'Université Paris II Panthéon-Assas, Academy on International Investment Disputes, Kuala Lumpur Regional Centre for Arbitration, Malasia. Ejercicio profesional en Derecho Médico, Derecho de Seguros y Derecho del Comercio Internacional e Industrial, en firmas de abogados y empresas internacionales en Francia, Singapur y Colombia. Contacto: felipetaba@gmail.com www. fr.linkedin.com/in/felipetabarescortes. 


\section{RESUMEN}

La Unión Europea y Colombia expidieron respectivas Reformas de la intermediación en seguros cuya vigencia definitiva comienzó a correr en ambos casos en el año 2018. No solo los requisitos de ejercicio de la profesión de intermediario en seguros fueron modificados (idoneidad, capacidad técnica y profesional), sino también las obligaciones de información que son propias a los distribuidores de contratos de seguro. El autor menciona así los antecedentes de estas reformas en el contexto en el cual fueron introducidas, para luego especificar cuál es concretamente el contenido de la Reforma de la Distribución de Seguros. Igualmente, se presenta una reciente jurisprudencia de la Corte Suprema de Justicia colombiana sobre este tema.

Palabras clave: Reforma; intermediación en seguros; reglamentación prudencial; Europa; Colombia; derecho comparado; ejercicio profesional; intermediarios 


\begin{abstract}
European Unión and Colombia had passed Reformations respectively to the insurance intermediation regulation that came into force on 2018. Intermediaries were submitted to modifications, not only in relation to the activity requirements, as suitability, technical qualification and professional ability, but also about the information obligations owed by all distributors of insurance contracts. The author describes the general background of the Reformations in the context on which they were made, to then designate the scope of these modifications. Furthermore, it is exposed a recent case-law from the Colombian Supreme Court in relation to the insurance intermediaries.
\end{abstract}

Keywords: Reformation; insurance intermediation; prudential regulation; Europe; Colombia; comparative law; professional ability; intermediaires

\title{
SUMARIO
}

INTRODUCCIÓN. 1. LA REFORMA DE LA INTERMEDIACIÓN EN EUROPA - 1.1. Antecedentes de la reforma - 1.1.1. Las razones de ser de la reforma - 1.1.1.1. Objetivo y necesidad de la reforma - 1.1.1.2. Extensión de la reforma - 1.1.2. La reforma en el contexto del mercado único de seguros de Europa - 1.1.2.1. Principios de libre prestación de servicios y de libertad de establecimiento - 1.1.2.2. El método de control - 1.2. La reforma en concreto 1.2.1. Competencia técnica - 1.2.2. Idoneidad-1.3. Protección de los usuarios - 1.3.1. La protección a través de la información - 1.3.2. El contenido de la obligación de información - 1.3.3. Extirpación del conflicto de intereses a través de la información - 2. LA REFORMA DE LA INTERMEDIACIÓN EN COLOMBIA - 2.1. Antecedentes de la reforma - 2.1.1. Las razones de ser de la reforma - 2.1.1.1 Extirpación del conflicto de intereses a través de la información - 2.1.1.1.1. Objetivo y necesidad de la reforma - 2.1.1.1.2. Extensión de la reforma - 2.1.2. La reforma en el contexto del mercado de intermediación en seguros de Colombia - 2.1.2.1 Principios de libertad contractual - 2.1.2.2 Principios de control prudencial de la intermediación - 2.1.2.2.1. El control delegado - 2.1.2.2.2 El control concentrado 2.1.2.2.3 El control sustantivo - 2.2. La reforma en concreto - 2.2.1. Requisitos de ejercicio - 2.2.1.1. Competencia técnica - 2.2.1.2. Idoneidad - 2.2.2. Protección de los usuarios - 2.2.2.1. La protección a través de la información - 2.2.2.2.2. El contenido de la obligación de información - 2.2.2.3. Prevención de los conflictos de intereses a través de la información - CONCLUSIONES - BIBLIOGRAFÍA. 



\section{INTRODUCCIÓN}

La Unión Europea y Colombia coincidieron en el año 2018 con la introducción definitiva de modificaciones al régimen propio de la intermediación de seguros. Así, el Parlamento Europeo y la Superintendencia Financiera de Colombia expidieron Reformas cuya vigencia definitiva tiene lugar en el año 2018, cuando se cumplen igualmente 500 años de la Reforma Protestante de Martin Lutero, el cual fue reconocido como un gran cambio teologico-politico que permitió una ruptura frente de la autoridad institucional tradicional y una difusión del conocimiento científico y religioso en los pueblos europeos ${ }^{1}$. Así como en la Europa del siglo XVI la reforma removió las bases ideológicas y políticas, en Colombia y en la actual Unión Europea, los temas de las obligaciones de información de los intermediarios de seguros, los requisitos de idoneidad, la capacidad técnica y profesional y el régimen de control fueron objeto de profundas modificaciones. Esta regulación es de gran importancia si se tienen cuenta los intereses que están en juego y el riesgo constante de en la actividad de intermediación de seguros concurran los elementos configurantes de captación masiva y habitual de dineros del público ${ }^{2}$.

La Reforma Europea se concentró en un aspecto que no es tradicionalmente objeto de procesos judiciales y que escapa por lo tanto a un intervencionismo garantista de los jueces como es la existencia e incidencia de los conflictos de interés en la distribución de seguros. En efecto, en lo que respecta a los deberes de información del intermediario de seguros se puede afirmar que el sistema judicial, así como la doctrina, han desarrollado parámetros claros sobre el comportamiento esperado del profesional de la intermediación en seguros. Sin embargo, como algunos lo han denunciado ${ }^{3}$, nuestro país estaba en mora de regular los conflictos de interés que pueden existir en el ejercicio de la actividad de intermediación de seguros y es por ello que la actividad reguladora del Parlamento Europeo, pionera en este sentido, debe tener un impacto directo sobre el marco legal de la distribución de seguros que existe en Colombia. En efecto, dicho ejemplo dado en unas jurisdicciones con sis-

1 Jonathan Bloch, Laury André (2015) La Réforme protestante, de Luther à Calvin: La réponse aux abus de la religion catholique, 50 minutes, Paris.

2 Concepto 2016132848-001 del 11 de enero de 2017 Superintendencia Financiera de Colombia Captación Masiva y Habitual y Actividad Aseguradora Ilegal, Prevención.

3 Bérmudez, D. (2013), El rol del intermediario de seguros en La industria aseguradora en Colombia, Avances en el siglo XXI, Fasecolda, Bogotá. 
temas financieros y jurídicos más maduros, puede servirnos para acortar el camino hacia una regulación más clara, orientada a los negocios y al mismo tiempo más protectora de los usuarios.

Nuestro país ha tenido firmes bases dogmáticas reflejadas en una particular manera de regular la actividad económica y financiera. No es menos relevante decir que las ideas que animan la infraestructura legal del país tienen su origen en el derecho comparado, más específicamente respecto de los países europeos frente a los cuales un pasado común es el fundamento primero de nuestros intercambios jurídicos intercontinentales. De ahí que la nueva Directiva de Distribución de Seguros del Parlamento Europeo y del Consejo sea en definitiva una fuente de derecho que, por su similitud con el espíritu que anima la regulación financiera colombiana, debe ser tenido en cuenta para los desarrollos posteriores, más específicamente sobre el ajuste normativo que debe hacerse sobre la distribución de seguros que en algunos aspectos es todavía muy rudimentario ${ }^{4}$.

Una presentación conjunta de ambas modificaciones debe realizarse puesto que a diferencia de otras áreas del derecho colombiano, en lo que respecta al derecho de seguros y su regulación, nuestro país ha seguido los requerimientos y estándares establecidos en la Comunidad Europea, como ha sido verificado en los análisis del $\mathrm{OCDE}^{5}$. Si bien puede decirse que la noción de intermediación de seguros que concretizó en ambos lados del Atlántico varios elementos comunes, la definición de intermediación en el lado europeo es más amplia. En efecto, la Reforma europea definió la intermediación a través de los verbos adaptación, redacción y celebración del contrato, mientras que la Reforma colombiana se limitó a definirla con los verbos asesoría, acompañamiento y adquisición. Esta diferencia de matices merece ser analizada (Conclusiones), pero antes es necesario presentar tanto los antecedentes como la extensión de la modificación introducida con la Directiva 2016/97 del Parlamento y el Consejo Europeo del 20 de enero de 2016 cuya vigencia fue en el mes de Mayo de 2018 (1) así como la de la Circular 050 de 2015 de la Superintendencia Financiera cuya vigencia definitiva tiene lugar en el mes de Diciembre de 2018 (2). Adicionalmente, una importante juris-

4 Para ver las propuestas de mejoramiento realizadas por el autor luego de analizar ambos sistemas, ver $\S$ III (Conclusiones).

5 OECD Publishing (2011) Insurance Regulation and Supervision in Asia and Latin America, 11 juin 2001, OECD, Paris, Pag. 92. 
prudencia de la Corte Suprema de Justicia de Colombia fue expedida el pasado 26 de junio de $2018^{6}$, referida al rol de la intermediación y la indemnización de siniestros, cuyo ratio descidendi es mencionado en la Sección $\S 2 ; 2.1 ; 2.1 .2 ; 2.1 .2 .1 .1)$ del presente estudio.

\section{LA REFORMA DE LA INTERMEDIACIÓN EN EUROPA}

\subsection{Antecedentes de la reforma}

En el 2017 no solo se cumplieron 500 años de la Reforma religiosa de Martin Lutero sino que además la Unión Europea decidió Reformar la intermediación en el mercado más grande de seguros del mundo, para buscar la protección de los consumidores y lograr el trato igualitario de los operadores de este sector económico. Estos objetivos loables cumplen con el espíritu de protección del individuo frente a las instituciones que en cierta medida corresponde a las preocupaciones religiosas que Lutero en su momento expresó ${ }^{7}$.

Es gracias a la intervención reguladora del Parlamento Europeo que hoy se puede afirmar, sin duda alguna, que la Unión Europea es el espacio continental supranacional más garantista del planeta. Con un ánimo renovador y unificador la Comisión Europea presentó una modificación de la antigua Directiva 2002/92/CE ${ }^{8}$ sobre la intermediación de seguros. El Parlamento consideró entonces rehacer en su integralidad dicho estatuto y expidió la Directiva 2016/97 del Parlamento y el Consejo europeos del 20 de enero de $2016^{9}$ de manera que un cuerpo único de reglas fue condensado para su aplicación uniformemente a los 28 Estados que integran esta Unión Continental que acoge más de 511 millones de habitantes, habla 7 lenguas oficiales y posee el PIB más alto del mundo por encima

Corte Suprema de Justicia Sala Civil SC3426-2018.

7 Simiele, Javier. (2010). Lutero y la política. Enfoques, 22(1), 71-90. Recuperado en 16 de agosto de 2018.

8 Directiva 2002/92/CE del Parlamento Europeo y del Consejo, de 9 de diciembre de 2002, sobre la mediación en los seguros (DO L 9 de 15.1.2003, p. 3).

9 2.2.2016 ES Diario Oficial de la Unión Europea L 26/19, Por el Parlamento Europeo, el Presidente M. Schulz, por el Consejo el Presidente, A.G. Koenders. 
de Estados Unidos y Japón. El mercado común de seguros es entonces el más complejo del orbe por el número de habitantes y de jurisdicciones subyacentes de forma que las modificaciones que han sido introducidas deben sin duda ser objeto de reflexión por los legisladores de países que, como Colombia, son herederos directos del espíritu equitativo y protector propio de los sistemas jurídicos europeos y que vemos reflejados nuestros códigos de Comercio, Civil y Financiero ${ }^{10}$.

Para entender hasta donde deseó realizarse una reforma de la intermediación de seguros y las razones subyacentes para que el legislador europeo decidiera intervenir en esta área es necesario presentar las razones que motivaron la reforma ((1.1.1.) para luego mencionar como ocurrió dicha reforma en el contexto del Mercado Único de Seguros de Europa (1.1.2.).

\subsubsection{Las Razones de ser de la Reforma}

La nueva Directiva Europea busca crear un cuerpo de normas que sean aplicables de forma común e igualitaria a todos los actores que tradicionalmente intervienen en este mercado, específicamente agentes, corredores, operadores de «bancaseguro», empresas de seguros, agencias de viajes y empresas de alquiler de automóviles, entre otros. Así, se elimina toda discriminación existente en el trato de los operadores dependiendo del canal de distribución de los contratos de seguro, asegurándose de esta manera que el nivel de protección del consumidor sea respetado por todos los distribuidores, particularmente en lo que concierne a las obligaciones de información del cliente. Es precisamente en este punto que se buscó mejorar la antigua Directiva de 1992 que no precisaba si la protección se extendía a todos los canales de distribución o solo a aquellos tradicionales. Así, la protección se extiende a las empresas de seguros que venden sus productos sin intermediarios y a los seguros afinitarios (accesorios a bienes de consumo, viajes y automóviles), operadores que anteriormente no estaban referidos en la norma y por lo tanto no sometidos a las obligaciones de información.

\subsubsection{Objetivo y necesidad de la reforma}

10 A pesar de que la tendencia contemporanea es a afirmar la individualidad y particularismo propio a nuestro sistema, el origen de basico sigue siendo el de la familia jurídica del derecho continental de origen romano-germanico: Gil, M. V. G. (2013). El derecho occidental del siglo XXI y el concepto de familia jurídica. Revista de derecho: División de Ciencias Jurídicas de la Universidad del Norte, (39), 30-57. 
Un diálogo fructífero entre los diferentes órganos supranacionales europeos tuvo lugar durante más de cuatro años para llegar hasta esta nueva regulación. El Parlamento Europeo, hospedado en la Ciudad de Estrasburgo, considerando que las turbulencias financieras de los últimos años habían mostrado la importancia de garantizar a los consumidores una protección eficaz, independientemente el sector financiero de que se trate. Así, en el seno de dicho Órgano Deliberativo Supranacional ubicado en el célebre edificio Louise-Weiss, los parlamentarios manifestaron la necesidad de reforzar la confianza de los consumidores y de uniformizar la protección de los individuos en todo el territorio de la Unión. Esto es particularmente esencial si se tiene en cuenta que la protección del individuo es primordial en el espíritu europeo, lo cual no es compartido en la misma medida por el Reino Unido, situación que explica la diferencia regulatoria entre ambos mercados y que ha generado una distorsión frente a la garantía de los derechos de los consumidores a ambos lados del canal de la Mancha luego del voto del Brexit de 2016, puesto que hay sin duda una diferencia en el eje sobre el cual giran los sistemas jurídicos. Mientas el centro de interés en Europa es el individuo y el profesional, el mercado lo es en 'la City”는 (Londres), la gran plaza financiera del Atlántico norte. Europa intenta por su lado resaltar por su individualidad y por ello perfila con más ahínco lo que es tradicionalmente suyo, la protección ciudadana y la regulación de las profesiones.

Dos objetivos comunes fueron privilegiados por el proyecto legislativo presentado por la Comisión Europea ${ }^{12}$. De un lado una protección acentuada del consumidor ${ }^{13}$, y de otro lado un trato igualitario para los intermediarios, mejorando el rendimiento del mercado. La Comisión buscó, con esta Directiva garantizar un mismo nivel de protección a todo tipo de consumidor dentro

11 Expresion utilizada en el mundo financiero para referirse a la ciudad de Londres, la mas grande y tradicional plaza financiera en seguros de Europa y del Mundo.

12 Propuesta de Directiva Del Parlamento Europeo Y Del Consejo sobre la mediación en los seguros (Refundición) /* COM/2012/0360 final - 2012/0175 (COD) */52012PC0360

13 Artículo 17, Principio general

1. Los Estados miembros garantizarán que los intermediarios de seguros o los distribuidores de seguros, cuando desarrollen actividades de distribución de seguros, actúen siempre con honestidad, equidad y profesionalidad, en beneficio de los intereses de sus clientes.

2. Sin perjuicio de lo dispuesto en la Directiva 2005/29/CE del Parlamento Europeo y del Consejo (14), los Estados miembros garantizarán que toda la información relativa al ámbito de la presente Directiva, incluidas las comunicaciones publicitarias, dirigidas por los distribuidores de seguros a los clientes o posibles clientes sea precisa, clara y no engañosa. Las comunicaciones publicitarias serán claramente identificables como tales.

3. Los Estados miembros garantizarán que los distribuidores de seguros no sean remunerados ni evalúen el rendimiento de sus empleados de un modo que entre en conflicto con su obligación de actuar en el mejor interés de sus clientes. En particular, un distribuidor de seguros no establecerá 
del mercado común europeo permitiéndoles beneficiarse de normas comparables. Quiso además el Órgano Ejecutivo Europeo, hospedado en la ciudad de Bruselas, promover un entorno equitativo y una igualdad de condiciones de competencia entre los intermediarios de seguros, independientemente de si estos están subordinados o no a una empresa de seguros. Considerando que el consumidor saldrá beneficiado si los productos de seguro se distribuyen a través de distintos canales e intermediarios vinculados de forma diferente con las empresas de seguros, el Parlamento aceptó el proyecto de Directiva propuesto en estos términos por la Comisión, bajo el entendido de que siempre se deben aplicar normas análogas en materia de protección del consumidor dentro de todos los estados que conforman el Bloque Continental.

\subsubsection{Extensión de la reforma}

Los Comisionados, dirigidos por Jean-Claude Juncker, siguiendo las preocupaciones expresadas por diferentes actores del mercado, quisieron que la Reforma tuviera en cuenta las diferencias existentes según los tipos de canales de distribución. Así, se tuvieron en cuenta no solo las características de los intermediarios de seguros que están obligados a ejercer la actividad de distribución de seguros exclusivamente con una o más empresas de seguros (intermediarios de seguros ligados), pero además las condiciones en las que se ejercen los distintos tipos de distribución. Por ejemplo, no en todos los casos se exige el registro de intermediarios, pero la Reforma permitió a los Estados de la Unión a imponer a los distribuidores de seguros que son responsable de la actividad de un intermediario determinado, que garantice que dicho intermediario cumple las condiciones de registro de la autoridad financiera/prudencial.

\subsubsection{La reforma en el contexto del mercado único de seguros de Eu- ropa}

Uno de los objetivos del Tratado del Constitutivo de la Unión Europea fue abrir los mercados de los países miembros de la Unión Europea para que, siguiendo el ejemplo de los beneficios que trajo la Comunidad Económica

ningún sistema de remuneración, de objetivos de ventas o de otra índole que pueda constituir un incentivo para que este o sus empleados recomienden un determinado producto de seguro a un cliente si el distribuidor de seguros puede ofrecer un producto diferente que se ajuste mejor a las necesidades del cliente. 
Europea, se permitiera un ingreso igualitario de todos los actores al más grande mercado del mundo a través de unos principios que aseguraran la competencia (1.1.2.1.) y un método de control específico (1.1.2.2.).

1.1.2.1. Principios de libre prestación de servicios y de libertad de establecimiento

En el Mercado Común Europeo de Seguros, todos los actores del mercado, empresas de seguros y reaseguros e intermediarios pueden prestar servicios en el territorio de la Unión a través de la denominada "Libre Prestación de Servicios" (LPS) o Pasaporte europeo. Así, para tener acceso al mercado de 511 millones de personas, al intermediario le basta con estar registrado en uno de los Estados miembros de la Unión. Este sistema innovador y revolucionario permitió una distribución acentuada de contratos de seguro por todo el continente beneficiando a los operadores tradicionales con una clientela potencialmente enorme, a los nuevos operadores con la posibilidad de ofertar servicios hasta ahora desconocidos en un determinado mercado nacional, y de manera general facilitó el garantizar una libre competencia supranacional que a la postre redundó en una mejoría del servicio que sin duda es tan útil para el acompañamiento de la creación de riquezas a través de contratos de seguros.

\subsubsection{El método de control}

Este pasaporte europeo fue mantenido en la Reforma de la Directiva 2016/97 aprobada por el Parlamento y el Consejo Europeo que establece que los intermediarios de seguros, reaseguros y seguros complementarios que son personas físicas deben ser registrados por la autoridad competente del Estado miembro en el que residan para que puedan de este modo acceder a todo el mercado europeo. Los intermediarios de seguros, reaseguros y seguros complementarios que sean personas jurídicas deben ser registrados por la autoridad competente del Estado miembro en que tengan su domicilio social o su administración central. En consecuencia, el registro en sus Estados miembros de origen permite a los intermediarios de seguros, reaseguros y seguros complementarios ejercer su actividad en otros Estados de la Unión en virtud de los principios de libertad de establecimiento y de libre prestación de servicios, siempre y cuando se hayan seguido unos procedimientos de notificación adecuados entre las autoridades prudenciales nacionales competentes. 
El control se ejerce principalmente a través del procedimiento bajo el cual se supervisa el cumplimiento de los requisitos profesionales estrictos respecto a la idoneidad, a la buena reputación, a la contratación de un seguro de responsabilidad civil profesional y a la capacidad financiera. Este control es entonces ejercido por la autoridad financiera o prudencial donde se encuentra domiciliado el intermediario. Cuando los intermediarios ejercen su actividad en distintos Estados miembros bajo el régimen de la libre prestación de servicios, la autoridad competente encargada de garantizar el cumplimiento de las obligaciones contempladas en la Directiva es la autoridad del Estado miembro donde está domiciliado el intermediario. Es de este modo que si la autoridad financiera / prudencial de un Estado miembro determina que en su territorio se está infringido alguna de las obligaciones de los intermediarios de seguros, debe informar de ello a la autoridad competente del Estado de donde es originario el intermediario, el cual tomar las medidas necesarias. Sin embargo, el Estado receptor de los servicios de intermediación conserva competencia para intervenir si el Estado de origen no toma las medidas adecuadas o si estas resultan insuficientes. De otro lado, la autoridad competente del Estado miembro de acogida debe asumir la responsabilidad de hacer cumplir las normas relativas a los requisitos de información del consumidor y las normas de conducta respecto de los servicios prestados dentro de su territorio.

Por su lado, los parlamentarios europeos, dirigidos por Antonio Tajani, aclararon que todas las medidas que adopten las autoridades financieras / prudenciales de los Estados miembros frente a los intermediarios de seguros deben respetar el principio de proporcionalidad, según la naturaleza, la gravedad y la complejidad de los riesgos inherentes a la actividad del distribuidor determinado, con independencia de la importancia que revista el intermediario para la estabilidad financiera del mercado.

\subsection{La reforma en concreto}

La Directiva, habiendo reforzado la protección del consumidor y el trato igualitario de sus operadores, limito su esfera de intervención al acto de intermediación en sentido estricto, es decir, únicamente para aquellas operaciones en las cuales se busca la contratación de una garantía de seguro con un operado habilitado para ello, el cual se encarga de la adaptación, redacción y celebración de un contrato de seguro. 
No hicieron parte del ámbito de aplicación de la Reforma, las actividades de aquellas personas que ejercen otra actividad profesional diferente a la intermediación, tales como los expertos fiscales, los contadores o los abogados, que asesoran en materia de seguros de forma accesoria en el marco de esa otra actividad profesional. No es tampoco el caso de aquellos que gestionan de forma profesional los siniestros en nombre de una empresa de seguros o de reaseguros, o que efectúan actividades de peritaje, ajuste, inspección y liquidación de siniestros. Finalmente, son también objeto de exclusión quienes facilitan información de carácter general sobre los productos de seguro, siempre que dicha actividad no tenga como objetivo ayudar al cliente a celebrar o a ejecutar un contrato de seguro. Frente a los operadores de la distribución cobijados por la Reforma la Directiva del Parlamento Europeo estableció unos requisitos de competencia técnica (1.2.1.) así como de idoneidad (1.2.2.).

\subsubsection{Competencia técnica}

Frente a los requisitos de ejercicio de la intermediación en seguros, la Directiva se fijó como objetivo el garantizar un elevado nivel de profesionalismo y competencia técnica por parte de los intermediarios de seguros, reaseguros y seguros complementarios y de los empleados de empresas de seguros y reaseguros que intervengan en la actividad de producción de contratos de seguros, ya sea en la fase preparatoria, durante la venta o con posterioridad a la misma. De esta manera, para el Parlamento Europeo, los conocimientos profesionales de los intermediarios y de los empleados de empresas de seguros deben estar en consonancia con el nivel de complejidad de esas actividades. Se exige entonces que los intermediarios de seguros conozcan las condiciones de las pólizas que distribuyen así como, en su caso, las normas y procedimientos para tramitar siniestros y quejas.

\subsubsection{Idoneidad}

En materia de la integridad exigible a los operadores de la distribución, el Parlamento en la exposición de motivos, siguiendo el proyecto presentado por la Comisión, se mencionó que el objetivo principal es contribuir a que el mercado de los seguros sea sólido y fiable, además permitir proteger adecuadamente a los tomadores de seguros. Entre estos 
requisitos se hallan el no tener antecedentes penales, particularmente determinados delitos como aquellos contemplados en la legislación en materia de servicios financieros, como los delitos contra la honestidad, los delitos de fraude, los delitos financieros y cualquier otro comportamiento contemplado en el Derecho de sociedades o en la legislación de quiebra e insolvencia.

\subsection{Protección de los usuarios}

El contrato de seguro, después de siglos de perfeccionamiento, se convirtió en un método de protección de las personas, las empresas y los entes territoriales. Es por ello que en los Estados Occidentales se permite su libre comercialización ${ }^{14}$ y se compensa esa libertad con una imposición de deberes, específicamente de protección, a través de la imposición de unas obligaciones de información (1.3.1.) que se concreta en un contenido específico de información que tiene que ser otorgada (1.3.2.).

\subsubsection{La protección a través de la información}

La protección de los clientes es uno de los principales objetivos buscados por los parlamentarios europeos con la reforma de la Directiva de Distribución de Seguros ${ }^{15}$. Se afirma que los clientes deben disponer de antemano de información clara sobre la condición en que actúan las personas que venden productos de seguro y sobre el tipo de remuneración que reciben. Tal información debe ser otorgada al cliente en la fase

14 No es el caso de los países de confesion islamica donde el funcionamiento de los seguros es diferente a los países occidentales y cuyos principios se subsumen en la noción Takaful de los seguros, la cual es una rama de las finanzas islamicas.

15 Artículo 18: Información general que deberá proporcionar el intermediario de seguros o la empresa de seguros. Los Estados miembros garantizarán que:

a) con suficiente antelación antes de la celebración de un contrato de seguro, los intermediarios de seguros proporcionen a los clientes la información siguiente:

i) su identidad y dirección, así como su condición de intermediario de seguros,

ii) si ofrecen asesoramiento en relación con los productos de seguro vendidos,

iii) los procedimientos contemplados en el artículo 14 que permitan a los consumidores y otras partes interesadas presentar quejas sobre los intermediarios de seguros y sobre los procedimientos de resolución extrajudicial contemplados en el artículo 15 ,

iv) el registro en el que esté inscrito y los medios para comprobar esa inscripción, y

v) si el intermediario representa al cliente o actúa en nombre y por cuenta de la empresa de seguros;

b) con suficiente antelación, antes de la celebración de un contrato de seguro, las empresas de seguros proporcionarán a los clientes la información siguiente:

i) su identidad y dirección, así como su condición de empresa de seguros,

ii) si ofrecen asesoramiento en relación con los productos de seguro vendidos,

iii) los procedimientos contemplados en el artículo 14 que permitan a los consumidores y otras partes 


\section{precontractual con la finalidad de darle a conocer cuál es la relación que existe entre la empresa de seguros y el intermediario y, según el caso, el tipo de retribución recibida por el intermediario ${ }^{16}$.}

\section{Pero esta obligación que en un principio se establece únicamente} respecto de los intermediarios, puede crear distorsiones en el mercado puesto que las empresas de seguros podrían buscar evitar las obligaciones de información por medio de la venta directa de seguros a través de personas contratadas por éstos. El Parlamento se aseguró entonces de que esto no sucediera e impuso igualmente a las empresas de seguros de informar al cliente la naturaleza de la remuneración que reciben sus

interesadas presentar quejas sobre las empresas de seguros, y sobre los procedimientos de resolución extrajudicial contemplados en el artículo 15 .

16 Artículo 19: Conflictos de intereses y transparencia

1. Los Estados miembros garantizarán que, con suficiente antelación antes de celebrarse un contrato de seguro, los intermediarios de seguros proporcionen al cliente, como mínimo, la información siguiente: a) si poseen una participación directa o indirecta del $10 \%$ o superior de los derechos de voto o del capital en una empresa de seguros determinada;

b) si una empresa de seguros determinada o una empresa matriz de dicha empresa posee una participación directa o indirecta del $10 \%$ o superior de los derechos de voto o del capital del intermediario de seguros;

c) por lo que se refiere al contrato ofrecido o sobre el cual se ha asesorado, si:

i) facilitan asesoramiento basándose en un análisis objetivo y personal,

ii) están contractualmente obligados a realizar actividades de distribución de seguros exclusivamente con una o varias empresas de seguros, en cuyo caso deberán informar de los nombres de dichas empresas de seguros, o bien

iii) no están contractualmente obligados a realizar actividades de distribución de seguros exclusivamente con una o varias empresas de seguros y no facilitan asesoramiento basándose en un análisis objetivo y personal, en cuyo caso deberán informar de los nombres de las empresas de seguros con las que puedan realizar, o de hecho realicen, actividades de seguros;

d) la naturaleza de la remuneración recibida en relación con el contrato de seguro;

e) si, en relación con el contrato de seguro, trabajan:

i) a cambio de un honorario, esto es, la remuneración la abona directamente el cliente,

ii) a cambio de una comisión de algún tipo, esto es, la remuneración está incluida en la prima de seguro,

iii) a cambio de cualquier otro tipo de remuneración, incluida cualquier posible ventaja económica ofrecida u otorgada en relación con el contrato de seguro, o

iv) sobre la base de una combinación de cualquiera de los tipos de remuneración especificados en los incisos i), ii) y iii).

2. Cuando el cliente deba abonar directamente el honorario, el intermediario de seguros informará al cliente del importe de dicho honorario o, cuando ello no sea posible, el método para calcularlo.

3. Si con posterioridad a la celebración del contrato, el cliente efectúa, en virtud del contrato de seguro, algún pago distinto de las primas periódicas y los pagos previstos, el intermediario de seguros facilitará también la información a que se refiere el presente artículo en relación con cada uno de esos pagos.

4. Los Estados miembros garantizarán que, con suficiente antelación antes de celebrarse un contrato de seguro, las empresas de seguros comuniquen al cliente el carácter de la remuneración recibida por sus empleados en relación con el contrato de seguro.

5. Si con posterioridad a la celebración del contrato, el cliente efectúa algún pago en virtud del contrato de seguro distinto de las primas periódicas y los pagos previstos, la empresa de seguros facilitará también la información a que se refiere el presente artículo en relación con cada uno de esos pagos. 
empleados por la venta de productos de seguro.

\subsubsection{El contenido de la obligación de información}

La protección de los clientes por la vía de la imposición de una obligación de información no se limitó a la calidad en la cual el operador distribuye los contratos de seguro, sino además respecto del contenido mismo del contrato de seguro. Así, antes de celebrar un contrato se exige que se le dé al cliente la información pertinente sobre el producto de seguro en sí mismo, de modo que el usuario pueda tomar una decisión con conocimiento de causa. Por ello, los documentos de información sobre productos de seguro deben facilitar una información estandarizada sobre los todos los productos de seguro (específicamente aquellos distintos del seguro de vida). La elaboración de tales documentos compete a la empresa de seguros correspondiente o, en caso de que el intermediario de seguros diseñe el producto de seguro, a dicho intermediario. El operador debe entonces explicar al cliente las características esenciales de los productos que vende y, por lo tanto, debe disponer de los recursos y del tiempo necesarios para ello. Si la Directiva admite que estos documentos sean otorgados de manera virtual, ello no obsta para que en cualquier caso el cliente pueda pedirlos en físico. En cualquier caso, el acceso a todos los documentos precontractuales debe ser gratuito.

El Parlamento Europeo buscó principalmente evitar la venta abusiva de productos de seguro. En efecto, la Directiva exige que todo contrato sea acompañado de una evaluación de necesidades y exigencias del cliente a partir de los elementos que respecto del riesgo le ha comunicado el usuario. De esta manera, para el Órgano Democrático Europeo ubicado en la ciudad de Estrasburgo, todo producto de seguro que se proponga a un cliente debe corresponder con las necesidades y exigencias de cobertura de riesgos que el cliente manifiesta, análisis que tiene que concretarse en un documento que tiene que ser presentado en una forma comprensible para permitirle al usuario tomar una decisión con conocimiento de causa. Más aún, si la intervención del intermediario o de la empresa de seguros se realiza en calidad de asesoría, el operador debe no solamente obtener la información sobre las necesidades y exigencias de cobertura del cliente, pero además debe aportar una recomendación personalizada explicando porque un producto de seguros determinado corresponde en 
mejor medida a esas necesidades y exigencias expresadas por el cliente.

Por último, el Parlamento Europeo deja un margen discrecional a los miembros de la Unión para determinar si la violación de la Directiva conlleva a la imposición únicamente de sanciones administrativas o de si puede además de ello imponerse sanciones de carácter penal. Sin embargo, señala que las sanciones pecuniarias tienen que tener un monto suficientemente elevado para neutralizar las ganancias realizadas o esperadas y tener un efecto disuasivo ${ }^{17}$, no solo respecto de las personas jurídicas, pero igualmente respecto de sus dirigentes.

\subsubsection{Extirpación del conflicto de intereses a través de la información}

El Comité Económico y Social Europeo dirigido por Staffan Nilsson, alertó en su Dictamen sobre el tema $\frac{18}{}$, la posible existencia de un conflicto de interés por parte de los operadores empleados o personas vinculadas y las empresas de seguros. En efecto, para el Comité Económico y Social, cuando el esquema de remuneración del personal de la empresa de seguros impone objetivos de venta, se crea una incitación a recomendar al cliente un producto que le genera más rentabilidad al intermediario. Es por ello que el Parlamento Europeo impuso en la Directiva a los Estados miembros la obligación de exigir que las políticas de remuneración practicadas por los distribuidores de productos de seguros respecto de su personal no entraben en su obligación de actuar en pro del mejor interés del cliente. Se busca así garantizar que el esquema de remuneración de las compañías de seguros disuada a sus intermediarios de realizar una recomendación no adaptada a las necesidades del cliente. Esta regla busca básicamente que los empleados de las empresas de seguros estén obligados, o por lo menos no estén impedidos, de presentar la información de manera imparcial, clara y no engañosa.

Otro punto esencial desarrollado por el Dictamen del Comité Económico y Social Europeo fue el concerniente a la necesidad de que se informe al cliente sobre el hecho de si el intermediario dispone o no de un análisis imparcial y personalizado del mercado de seguros. En efecto, solo luego de un análisis imparcial e individualizado del mercado de seguros se puede afirmar que se

17 Lo cual se acerca a la noción de daños punitivos.

18 Avis du Comité économique et social européen sur 1 «Proposition de directive du Parlement européen et du Conseil sur l'intermédiation en assurance (refonte)» COM (2012) 360 final, 2012/0175 (COD) 2013/C 44/16 Rapporteure: Mme Ellen Nygren. 
otorgó una información imparcial al usuario. Por ello, el Parlamento Europeo definió la noción de análisis imparcial y personalizado como aquel en el cual el intermediario ha tenido en cuenta, en su labor de asesoría del cliente, todas las particularidades del mercado para un ramo específico de seguros. Así, el intermediario debe analizar un número suficiente de contratos, el número de empresas establecidas en el mercado en dicho ramo, la parte del mercado que le corresponde a cada empresa, el número de productos de seguro relacionados a ese tipo de coberturas y las características específicas de esos productos. Es así, como el Órgano Legislativo Europeo creado en el Tratado de Maastricht, permitió a los Estados miembros de la Unión imponer a los intermediarios de seguros la obligación de proveer al cliente dichas precisiones respecto del mercado y de todos los contratos que dichos intermediarios distribuyen, de realizar una distribución de seguros sobre la base de un análisis imparcial y personalizado del mercado.

\section{LA REFORMA DE LA INTERMEDIACIÓN EN COLOMBIA}

Colombia, pionera en muchos sentidos en el dominio financiero, expidió la Circular Externa 050 de 2015 en la cual la Superintendencia Financiera de Colombia introdujo cambios sustanciales en la regulación de la intermediación de seguros, reformando y completando el derecho existente. De esta forma, con el fin de alinear el marco jurídico colombiano a los estándares internacionales en materia de intermediación de seguros y de fortalecer los mecanismos de protección de tomadores-asegurados-beneficiarios, la Superintendencia Financiera de Colombia consideró necesario impartir instrucciones relacionadas con la actividad de intermediación de seguros respecto de los estándares de idoneidad aplicables a las personas que ejercen la intermediación de seguros, los requisitos de información destinada a dichos consumidores, la publicidad $\mathrm{y}$ transparencia de las personas autorizadas por las entidades aseguradoras y los corredores de seguros para ejercer la intermediación de seguros, además de unas medidas de gobierno cororativo asociado a estas materias. Es necesario entonces mencionar cuales fueron los antecedentes de le reforma ((2.1.), para luego poder analizar la reforma en concreto (2.). 


\subsection{Antecedentes de la Reforma}

La distribución de productos de seguro es particular en el sentido que el producto se concibe por una persona que es diferente a aquella que funge como productor (asegurador). Es por ello que si existen reproches éticos, estos no pueden de manera genérica le ser atribuidos al asegurador. Sin embargo, el asegurador será excepcionalmente responsable si existe un mandato con representación que implica la representación, como cuando se ha otorgado mandato de suscripción o de gestión al intermediario, de manera que las faltas éticas del distribuidor pueden ser directamente imputables al asegurador. Es el caso particularmente del riesgo moral en la selección de coberturas, o respecto de la gestión de garantías e indemnizaciones, circunstancias en las que no se pueden ver inmersos sino aquellos que portan la calidad de Partes en el contrato de seguro ${ }^{19}$. Es por ello que en estos casos, desde el punto de vista de la deontología contractual, la calidad de distribuidor es asimilable a aquella de productor, porque los actos irrespetuosos de la ética son cometidos por una persona que gozaba de la calidad de representante del asegurador-productor. El rol del distribuidor impone entonces la necesidad al derecho de regular su comportamiento teniendo en cuenta tales particularidades y es por ello que presentaremos las razones que imponen la reformulación de las reglas de la distribución de productos de seguro (2.1.1.) para luego mencionar cual es el contexto en el cual se realiza una tal Reforma (2.1.2.).

\subsubsection{Las razones de ser de la reforma}

El asegurador está sometido a la voluntad del asegurado puesto que él debe construirse una idea del riesgo a través de la declaración que realiza el tomador ${ }^{20}$. Es por ello que en términos generales el análisis deontológico del contrato de seguro se ha limitado tradicionalmente a lo que el profesor Luc Mayaux llama la "ética de la solicitud" haciendo referencia a que los Códigos de Seguros occidentales han no sancionan sino los comportamientos contrarios a la ética teniendo como base la declaración de riesgos realizada por el asegurado-tomador, sin referencia alguna a la oferta de seguro emanada

19 Luc Mayaux Ethique et offre d'assurance, Revue générale du droit des assurances, 01/04/2000, n 2000-2, Lextenso, RGDA2000453.

20 Picard et Besson (1982) Le contrat d'assurance, LGDJ, 5e éd. n 42, citado por L. Mayaux, Op. cit. 2000 . 
del asegurador o del intermediario de seguros ${ }^{21}$.

Pero este vacío no significa de ninguna manera que no existan consideración éticas a tener en cuenta respecto del comportamiento del asegurador/intermediario en el momento de la conclusión del contrato y es por ello que cada vez son más estrictas las obligaciones informativas por parte de las compañías de seguros. Es en este contexto que llega la Reforma de la intermediación para transgredir fronteras tradicionalmente infranqueables, a la manera en que la Reforma Luterana lo logró en la Europa del siglo XVI. De este modo, Colombia ha buscado solventar dicho vacío a través de la imposición de limitaciones al tráfico económico en el sector de seguros, particularmente en el Estatuto Orgánico del Sistema Financiero que en su artículo $207 \underline{22}$ establece prohibiciones como:

- La colocación de un seguro bajo un plan distinto al ofrecido, con engaño para el asegurado;

- la cesión de comisiones a favor del asegurado;

- el ofrecimiento de beneficios que la póliza no garantiza o la exageración de éstos,

- el hacerse pasar por agente o representante de una compañía sin serlo;

Se vislumbra entonces un cambio en los estándares deontológicos, concentrado básicamente en la necesidad de garantizar la transparencia en las transacciones, definida desde la claridad, la comprensibilidad y la exhaustividad del texto contractual ${ }^{23}$. Esta transparencia es especialmente relevante en la etapa precontractual en la cual se imponen obligaciones de información impregnadas del principio de buena fe, la cual impone una negociación leal y absteniéndose de comportamientos maliciosos, otorgando todos los datos relevantes ${ }^{24}$. Es de esta forma que una corriente reformadora viene imponiéndose, no en los Códigos de 21 Op. cit. Mayaux, L. (2000).

22 Aunque podemos decir que el objetivo de este texto es la protección de la libre competencia, al estipularse en dicha norma que: "en general todo acto de competencia desleal, dará lugar a la suspensión de la sociedad corredora, de la agencia o del agente responsable".

23 Vivas Diez, G. J. (2014) Transparencia en los contratos de seguros: Cláusulas e información precontractual, Revista Ibero-Latinoamericana de Seguros, RIS, Bogotá, Universidad Javeriana, 41(23): 39-80.

24 Op. cit. Vivas Diez, G. J. (2014). 
Seguros del siglo pasado, mas anclados en una lógica institucionalista del contrato de seguro, sino por parte de las regulaciones de las Autoridades Prudenciales o en los Códigos de Protección del Consumidor. Empieza entonces a establecerse una ética de la oferta de seguro dentro de una corriente reformadora a la cual no es ajena nuestro país. Para ilustrar esta corriente es entonces necesario manifestar cual es el objetivo que anima la Reforma (i) para luego manifestar cual es la extensión de dicha modificación (ii).

2.1.1.1 Extirpación del conflicto de intereses a través de la información

\subsection{Objetivo y necesidad de la reforma}

La preocupación principal de los grupos profesionales, de las autoridades prudenciales y de control y de los juristas en general es evitar que una visión personal y oportunista de la ética, tan propia de nuestro país, se substituya a la ética impuesta por el derecho. Pero la preocupación de asegurar el imperio de una disciplina profesional que se imponga sobre la ética de la conveniencia no se garantiza satisfactoriamente por la vía de la creación de una regla general imponiendo deberes éticos que luego debe ser aplicada por el juez, el tribunal ético o la autoridad prudencial, necesitando una concretización e individualización de la conducta contraria a la ética, procedimiento que es muy engorroso y riesgoso frente a profesionales del derecho cada vez más inescrupulosos y capaces de argumentar toda suerte de disparates. Si bien la regulación colombiana había avanzado ${ }^{25}$ calificando algunos textos contractuales como abusivos o lesivos para el tomador ${ }^{26}$, a falta de bases de datos científicas, de jueces rigurosos y de profesores de derecho diligentes que aseguren la aplicación uniforme de las reglas jurídicas, muchos litigantes colombianos se creen legitimados para argumentar entuertos inexpugnables y en medio del caos procesal colombiano esa labor de concretización del tipo disciplinario en blanco se ve claramente amenazada. En los tribunales colombianos los litigantes justifican hechos contrarios a la deontología profesional y a la ética colectiva, a través de la utilización artificiosa de nociones de debido proceso probatorio y de buena fe, mientras que en ausencia de una concreta definición normativa, los operadores jurídicos

25 Op. cit. Vivas Diez, G. J. (2014).

26 De conformidad con lo establecido en el parágrafo del artículo 11 de la Ley 1328 de 2009, las estipulaciones contractuales que contravengan lo previsto en la ley se entenderán por no escritas o sin efectos respecto del consumidor financiero. 
tienen que echar mano de conceptos mucho más vacuos como el orden público, el abuso del derecho y la teoría de la causa contractual ${ }^{27}$, para poder impartir justicia deontológica. Todo esto no hace sino sumarle caos a la ya muy afectada estabilidad jurídica de Colombia, lo cual ha generado oprobios a la justicia de tamaño continental como es el caso de los grandes escándalos de corrupción en los proyectos de inversión internacional, los falsos cirujanos y las pirámides de Ponzi, o de tamaño nacional como la contratación de la carrera 26 de Bogotá, Foncolpuertos, Saludcoop e interbolsa.

Pero no es porque en algunos casos los montos en riesgo sean menores o se trate contratos limitados a ciertos dominios económicos, que la vigilancia pueda desaparecer. Por el contrario, tratándose de los seguros, cuya incidencia en la financiación de la economía hacen de éste un sector de importancia sistémica, se exige que la labor de la autoridad prudencial sea más ardua y apurada. Por ello es que el control del comportamiento de los intermediarios es vital, teniendo en cuenta que un porcentaje importante de la distribución de seguros se realiza por estos medios ${ }^{28}$ de manera que, solo por citar algunos ejemplos, los comportamientos tendientes a dejar transcurrir la prescripción, la estipulación de cláusulas que se saben nulas y los conflictos de interés asegurado-intermediario-asegurador deben controlarse a través no solamente de la redacción de normas claras identificando los comportamientos reprochables, sino también dando a la autoridad prudencial plenas facultades y recursos necesarios para hacer control financiero. Una cosa es no estar de acuerdo con una norma o una jurisprudencia, y otra muy diferente contrariar el derecho a sabiendas que los usuarios no podrán, no tendrán el tiempo o los recursos para reclamar sus derechos o incluso sabiendo que las multas serán mucho menores a los beneficios económicos que pueden surgir del acto fraudulento. Por ello, la regulación prudencial, el fortalecimiento de la Superintendencia Financiera y el robustecimiento de su capacidad punitiva son bienvenidas en el país de los abusos al individuo.

La información de los usuarios y la lucha contra los conflictos de interés son de particular importancia en la intermediación de seguros y hasta antes de la Reforma ${ }^{29}$ solo existían normas de información general, sin 27 Op. cit. Mayaux, L. (2000).

28 Fasecolda (2018) Los costos de la intermediación en Colombia ascendieron a un 15\% solo para mayo de 2018, Fasecolda, Cifras mayo 2018, Bogota.

29 Tascón Ortiz, J. B. (2015) La responsabilidad civil de los intermediarios de seguros, UPB Tesis de 
que se especificara en concreto como debía ser advertida la posibilidad de conflicto ético de la persona que se encuentra asesorando al usuario. Si bien existe la obligación de las entidades financieras de dar educación a los clientes y explicar el alcance de las coberturas exclusiones, ninguna norma exigía al intermediario de valorar si el producto de seguro era apropiado a las exigencias de cobertura del tomador, ni de orientarlo en la selección del producto más apropiado a sus necesidades ${ }^{30}$. Además, en el debate público colombiano se mencionó el riesgo proprio a los contratos distribuidos por intermedio de entidades bancarias, existiendo dudas respecto de las aseguradoras que pertenecen al mismo grupo del banco o de los empleados bancarios que no tienen claridad sobre los productos que están vendiendo ${ }^{31}$. La falencia regulatoria es evidente porque si bien se impone otorgar información cierta, clara, oportuna, confiable y suficiente, suministrada en concordancia con el contenido del contrato, además de la publicación de toda la información relativa a productos y servicios, dichas obligaciones solo eran predicables respecto de las sociedades corredoras de seguros, e inaplicables a las agencias y a los agentes ${ }^{32}$.

Los sectores profesionales subrayaron además la necesidad de que desde la regulación se exija un nivel académico y de experiencia de los operadores de la distribución de seguros ${ }^{\frac{33}{}}$, puesto que las modificaciones fragmentarias de las reglas deontológicas habían lamentablemente hecho desparecer de la ley el concepto de idoneidad y de profesionalización del intermediario de seguros $\frac{34}{}$. Más aun, la aparición de nuevos canales de comercialización $\frac{35}{}$, demandan una exigente labor del regulador y del supervisor para poder lograr el justo equilibrio entre el crecimiento de dicho sector y la imposición de reglas de conducta ${ }^{36}$. Calificada como

Grado Repository, Universidad Pontificia Bolivariana, Bogota.

30 Op. cit. Vivas Diez, G. J. (2014).

31 (2015) El debate que tendrán que enfrentar las aseguradoras. El representante a la Cámara David Barguil anunció control político para corregir algunas prácticas en las empresas aseguradoras y le dio un tirón de orejas a la regulación de seguros. Revista Dinero 9/4/2015.

32 Pues éstos no estaban bajo la inspección y vigilancia de la Superintendencia Financiera de Colombia, excluidos por lo tanto de cumplir con la normativa: Op. cit. Bermúdez, D. (2013).

33 Meneses Paternina, J. (2014) El Nuevo rol del intermediario de seguros, $2^{\circ}$ Congreso Internacional de Seguros: Actuales paradigmas jurídicos, Fasecolda, Santa Marta Mayo de 2014, recuperado el 20/08/2018.

34 Op. cit. Bermúdez, D. (2013).

35 Citando como ejemplos, los bancaseguros, corresponsales, distribuidores online, venta telefónica, superficies comerciales, en: Montealegre Escobar, J. O. (2016) Futuro de la Intermediación de Seguros en Colombia, 3 Congreso Internacional de Derecho de Seguros, Fasecolda, Pereira, mayo 5 de 2016 Presidente Ejecutivo ACOAS, 3 Congreso Internacional de Derecho de Seguros Fasecolda, recuperado el $20 / 08 / 2018$. Ibidem. 
anacrónica ${ }^{\frac{37}{}}$, la normativa colombiana se limitaba a describir los tipos de intermediación aceptados en nuestro ordenamiento y las actividades que se les autoriza desarrollar, a pesar de que el contrato de seguro es un activo intangible ${ }^{38}$ que exige que los de operadores de la distribución sean altamente capacitados, con conocimientos claros de los productos que ofrecen, para que pueda ilustrar los usuarios sobre una adecuada decisión de aseguramiento ${ }^{39}$.

Además, no existía una obligación clara del intermediario de seguros de proveer al consumidor, previamente a la celebración del contrato, el estatus en que actuaba como intermediario (si representando el cliente o la aseguradora), ni de todos los costos asociados al contrato de seguros, incluida su remuneración ${ }^{40}$. Y ello a pesar de que la información sobre el rol del intermediario es necesaria para reducir el riesgo de los conflictos de intereses y asegurar que el operador conserve su objetividad e imparcialidad en el análisis del mercado ${ }^{41}$.

El concretizar los deberes profesionales en comportamientos deseados/ reprochables es por el momento la técnica adecuada de control que permite al mismo tiempo evitar desestimular el crecimiento económico del sector y el control de los actores y operadores. En efecto, la autorregulación por los actores del sector no es suficiente, por no decir baladí. La autorregulación fomenta áreas sin control efectivo en las cuales la desprotección de los clientes termina, sin lugar a dudas, en el defraudamiento de los intereses de la sociedad y en el desprestigio del sistema financiero en general. Particularmente, se ha expresado gran preocupación por la necesidad imperiosa de profesionalización de la intermediación en seguros ${ }^{42}$ que va necesariamente de la mano con la idoneidad y la competencia intelectual y académica de los operadores. Pero además, aumentar la confianza de los consumidores y profesionales, así como el acercamiento hacia los estándares internacionales de regulación del sistema financiero, específicamente aquellos establecidos en el OCDE, son objetivos a los que la Reforma de la intermediación de seguros permitirá mejorar, si la Superintendencia Financiera se concentra en la aplicación rigurosa de la nueva Circular 50

37 Clavijo, L. (2015, septiembre 15). La intermediación de seguros en Colombia debe ser profesionalizada. Revista Fasecolda, 160, 36-39, recuperado el 20/08/2018.

38 Ibid.

39 Ibid.

40 Op. cit. Bermúdez, D. (2013).

41 Ibid.

42 Op. cit. Montealegre Escobar, J. O. (2016). 
de 2015 cuya vigencia definitiva tiene lugar el próximo mes de diciembre de 2018.

\subsection{Extensión de la reforma}

Reaccionando a las situaciones de hecho que acaban de enumerarse, la Superintendencia Financiera buscó complementar las pocas normas que incipientemente regulaban el tema de la intermediación en seguros en Colombia. Es por ello que la Superintendencia Financiera buscó, a través de la Circular Externa 050 de 2015 modificatoria de la Circular Básica Jurídica, alinear el marco jurídico colombiano a los estándares internacionales en materia de intermediación de seguros y fortalecer así los mecanismos de protección de tomadores-asegurados ${ }^{43}$. Se consideró entonces necesario introducir reglas orientadas a regular la actividad de intermediación de seguros respecto de los estándares de idoneidad aplicables a las personas que ejercen la intermediación de seguros, de los requisitos de información, de la publicidad y la transparencia, además de establecer medidas de gobierno corporativo asociado a estas materias.

Adicionalmente, se introdujo el Sistema Unificado de Consulta de Intermediarios de Seguros -SUCIS, para proporcionar información relevante acerca de las personas que ejercen la intermediación de seguros. Sin embargo, la Superintendencia Financiera continuó con su política de delegar el control de dichos distribuidores aclarando ${ }^{44}$ que las entidades aseguradoras y los corredores de seguros serán los únicos responsables porque la información ahí publicada sea completa, veraz y actualizada. Esta situación es irracional y contradictoria con los deberes de inspección, vigilancia y control que la ley le impone a éste organismo, además de ser ajena a los objetivos prudenciales que se establecen en el OCDE.

43 Aunque es muy discutible si la protección se limita a los consumidores, puesto que la tendencia actual en las democracias occidentales es a otorgar esta protección como la regla general y no como la excepcion. Al respecto ver: Tabares Cortés, F. (2017). La reforma del Código Civil Francés. Un proemio al cambio estructural de los principios de derecho privado del Código Napoleónico. Revista Verba Luris, (38), 155-169.

44 Concepto 2016007323-001 del 8 de marzo de 2016, Superintendencia Financiera de Colombia, Sistema Unificado de Consulta de Intermediarios De Seguros-SUCIS, deber de información, alcance. 


\subsubsection{La reforma en el contexto del mercado de intermediación en seguros de Colombia}

Hasta antes de la expedición de la Circular 50 de 2015 los juristas y algunos operadores jurídicos habían buscado inculcar obligaciones informativas, de idoneidad y de lucha contra los conflictos de interés a los intermediarios de seguros a través de una integración de normas propias a la protección del consumidor. Este movimiento interesante y valido pudo tener (y tiene aún sobre algunos aspectos no incluidos en la Reforma) efectos deseados, al comparar el seguro a un bien objeto de distribución material. Pero esta comparación que busca superar un vacío normativo, genera un riesgo de interpretación por la fragmentación y dispersión normativa y un riesgo especulativo puesto que los apoderados de las entidades enjuiciadas buscan deshacerse de dicha imposición de deberes generales haciendo hincapié en la especificidad de este producto financiero, lo cual es reprochable y frente a ello la llegada en vigencia de la reforma es bienvenida, así como la interpretación judicial que hace de todos nosotros unos beneficiarios del control financiero. La especificidad del producto de seguro se ve reflejada en los principios que la gobiernan, específicamente la libertad contractual (2.1.2.1) y el Control Prudencial de la Intermediación (2.1.2.2).

\subsubsection{Principio de libertad contractual}

El legislador Colombiano decidió hacer de nuestro Código de Comercio, y más concretamente de las reglas de distribución de seguros, unas normas de aplicación directa que no pueden ser desconocidas por las partes del contrato, situación que es contraria a otras jurisdicciones donde el código no tiene sino una función supletiva de la voluntad de los contratantes. Esta escogencia puede venir de la desconfianza del legislador en los comportamientos amañados de los contratantes o de la imperiosa protección de ciertos sectores. En cualquier caso, la regla subyacente a nuestros códigos de derecho privado es la libertad contractual que irradia las relaciones entre los particulares sobre los aspectos no regulados por dichos códigos (o aquellos en que se autoriza expresamente su subrogación). Se tiene entonces un sistema de marcos jurídicos frente a los cuales se establece el área en la cual puede ser ejercida la voluntad ciudadana. Ese marco está constituido por las normas de protección del asegurado-tomador, así como por aquellas que imponen obligaciones a los operadores-prestadores. 
De esta manera, unas normas generales ${ }^{45}$ otorgaron derechos a los consumidores de elegir los libremente los bienes y servicios que requieran, además el derecho a recibir educación sobre sus derechos y las formas de hacer efectivos esos derechos ${ }^{46}$. Igualmente, dichas normas impusieron unas obligaciones de actuar con diligencia en el ofrecimiento de sus productos de manera que se otorgue la información necesaria, con transparencia y oportunamente ${ }^{47}$. Sin embargo, esas reglas eran para evitar los abusos de las partes. Por ejemplo, se advierte que la obligación de obrar fielmente se limita a la ejecución del contrato ${ }^{48}$ de manera que los comportamientos reprochables cometidos antes o por fuera de la conclusión de un contrato de seguro están por fuera de la frontera de delimitación de la libertad contractual, situación que fue parcialmente resuelta con la introducción de la Reforma.

Además de ello, dicho principio de libertad contractual se ve reflejado en las reglas de la remuneración de los intermediarios, puesto que la determinación de las comisiones, formas de pago y demás condiciones se hace de conformidad con los convenios que libremente ${ }^{49}$ celebren intermediarios y entidades aseguradoras ${ }^{\underline{50}}$. La libertad contractual también se manifiesta en la posibilidad que tienen los intermediarios de desarrollar su actividad en beneficio de otras entidades aseguradoras para negocios ocasionales $\frac{51}{}$, lo que a su vez significa que los pactos de exclusividad estén restringidos respecto del agente independiente ${ }^{\underline{52}}$. Así mismo, se prohíbe pactar cláusulas de exclusividad que le impidan al agente independiente celebrar contratos con varias compañías de seguros o sociedades de capitalización $\frac{53}{}$, de manera que aquí la libertad contractual se manifiesta precisamente en la ausencia de ella.

45 Un muy completo repertorio de las normas generales y otras mas específicas sobre los contratos de seguros lo encontramos en: Vivas Diez, G. J. (2014) Transparencia en los contratos de seguros: Cláusulas e información precontractual, Revista Ibero-Latinoamericana de Seguros, RIS, Bogotá, Universidad Javeriana, 41(23): 39-80.

46 Articulo $3^{\circ}$, Ley 1480 de 2011.

47 Título I, Ley 1328 de 2009.

48 Op. cit. Tascón Ortiz, J. B. (2015).

49 Decreto 2555 de 2010, Art. 2.30.1.1.4.

50 Decreto 2605 de 1993, articulo 4, ahora vigente por bajo el Decreto 2.30.1.1.4 del Decreto 2555 de 2010 .

51 Como se menciona respecto de las agencias de seguros en el Decreto 2555 de 2010 (Art. 2.30.1.1.4). Esta libertad también es analizada en: Op. cit. Vivas Diez, G. J. (2014).

52 Op. cit. Vivas Diez, G. J. (2014).

53 Ibid. 
Pero esta libertad contractual también puede ser la base para realizar una distinción entre las obligaciones que pertenecen a los intermediarios y aquellas pertenecientes a la aseguradora. La Corte Suprema de Justicia ha en efecto analizado este punto particularmente en la Sentencia de la Sala Civil de 26 de junio de $2018^{\frac{54}{4}}$ para concluir que el agente de seguros, si bien cuenta con la representación de la aseguradora, no hace parte del contrato de seguro. Así, luego de que el asegurado fue indemnizado por el asegurador, un segundo pago realizado por el intermediario (creyendo equivocadamente pagar el siniestro) debe ser devuelto por el asegurado. Para la Corte, el pago adicional realizado por la agencia no se efectuó en ejecución del contrato de seguro, ni seguía una instrucción de la aseguradora. Por ello, dicho monto estuvo desprovisto de causa ya que en el momento en el que el segundo pago fue realizado, el contrato de seguro ya había sido extinto con el primer pago del siniestro realizado por la aseguradora. Es de esta manera que para la Sala Civil, los intermediarios no están llamados a responder por los perjuicios causador por la mora de las aseguradoras en indemnizar el siniestro, al no ser parte en el contrato de seguro, a pesar del mandato con representación. Al no haber entonces un fundamento contractual, el segundo pago realizado por el intermediario estuvo desprovisto de causa y se ordenó entonces ser reembolsado. Lo anterior explica por qué el contrato de seguro, en ausencia de prestaciones anexas por parte del intermediario, es el marco dentro del cual se entienden adquiridas las obligaciones de las partes, de manera que una indemnización inicial extingue las obligaciones del asegurador y ninguna obligación adicional puede ser predicable del tercero interviniente (el intermediario) para justificar el segundo monto pagado al asegurado ${ }^{55}$.

\subsubsection{Principio de control prudencial de la intermediación}

El control prudencial de los intermediarios de seguros es ejercido de manera indirecta por la Superintendencia Financiera a través del control delegado (2.1.2.2.1) por los jueces civiles, administrativos y la Superintendencia Delegada con Funciones Jurisdiccionales a través del control concentrado (2.1.2.2.2) y por los jueces en general a través de la responsabilidad civil (2.1.2.2.3).

\footnotetext{
54 SC3426-2018.

55 Corte Suprema de Justicia, Sala Civil, 26 de junio de 2018 SC3426-2018.
} 


\subsection{El control delegado}

Si bien el incumplimiento de las normas sobre protección al consumidor son sancionadas por la Superintendencia Financiera, el legislador colombiano, deseando centralizar la tarea de control de las entidades materialmente sometidas a su vigilancia, decidió delegar el control de los intermediarios de seguros en las personas jurídicas que expiden contratos de seguro. Así, argumentando que las agencias y los agentes de seguros tienen la representación de las compañías de seguros, estas compañías son encargadas por el legislador de ejercer el control de los intermediarios de seguros expidiendo una autorización de distribución ${ }^{\frac{56}{6}}$. En consecuencia, son tales compañías quienes deben velar por que las agencias y agentes que las representan cumplan con los requisitos de idoneidad y por qué se dé cumplimiento al régimen de inhabilidades e incompatibilidades a que se encuentran sujetos, además de que responderán solidariamente por la actividad que éstos realicen ${ }^{57}$. De esta forma, el legislador colombiano, confundió dos criterios distintos, puesto que la existencia de un mandato con representación o sin representación es utilizado por la doctrina y los operadores jurídicos con el único objetivo de suplir ciertas necesidades interpretativas como el determinar el momento en el cual se tiene por cumplida la obligación de pago de la prima por el tomador. Confunde así pues el legislador un criterio puramente de disciplina contractual con las exigencias deontológicas, externas al contrato de seguro, referidas al respeto o no de las obligaciones de probidad e idoneidad del intermediario de seguros ${ }^{58}$. Más aun, el legislador delegado, con este galimatías de control delegado le da la espalda a la imperiosa rigurosidad que debe guiar a la Autoridad Prudencial, sacrificando sus posibilidades de intervención en beneficio de las personas a quienes más les interesa distribución de seguros, es decir a las compañías de seguro, pues es una falacia decir que el control solo beneficia a los clientes. Si bien en el mercado muchas entidades hacen gala de su compliance con la regulación de la actividad de seguros, nada excluye la hipótesis que por

56 Ley 510 de 1999 Artículo 101.

57 Ibidem.

58 Este criterio es discutible si se tiene en cuenta que una parte considerable de la distribución se realiza por operadores que no tienen representación o solo un mandato limitado respecto de las compañías de seguros, como es por ejemplo la hipótesis del momento en el cual se entiende recibida la prima para efectos de analizar la fecha del cumplimiento de dicha obligación por el tomador y el mandato sin representación. Sobre el particular ver: Concepto No 1998045982-2. Octubre 23 de 1998, Superintendencia Financiera de Colombia, Primas, Responsabilidad en su Recaudo por Corredores de Seguros. 
cerciorarse de obtener un determinado mercado la compañía de seguros omita supervisar diligentemente sus distribuidores, circunstancia especialmente riesgosa en el ramo de vida y el mercadeo telefónico, puerta a puerta o por internet. Más aun, con esta delegación el legislador delegado colombiano ha desconocido los criterios del OCDE, según los cuales el objetivo principal del control prudencial sobre el mercado de seguros se debe centrar no solamente en la protección de tomadores, asegurados, beneficiarios y terceros y en el control de solvencia de los actores, pero también en la supervisión de la conformidad de los contratos (incluyendo los mandatos de intermediación) con la ley ${ }^{59}$. Pero si la autoridad prudencial, en nuestro caso la Superintendencia Financiera, limita su poder de intervención no hay quien se encargue de imponer el respeto de los estándares comportamentales si no es por los jueces civiles en los casos en que ello lo amerita, es decir, cuando surgen perjuicios antijurídicos. Pero este control judicial deja por fuera una multitud impresionante de contratos que no llegan al control judicial por la pirámide de litigiosidad que pervierte nuestro sistema judicial ${ }^{60}$.

Siguiendo este mismo criterio, en la Reforma introducida con la Circular 050 de 2015, se extendió la competencia de los corredores de seguros para imponerles el control de los intermediarios personas naturales que ejercen la distribución. Así, se estableció ${ }^{61}$ que corresponde a la junta directiva de los corredores de seguros establecer las políticas y aprobar los procedimientos necesarios para garantizar el cumplimiento de los requisitos de idoneidad de las personas naturales vinculadas que distribuyen contratos de seguros. Así, las juntas directivas de los corredores son responsables del cumplimiento de los deberes de información par parte de los intermediarios. Subsiguientemente, la Superintendencia Financiera ejerce un control directo sobre dichas juntas directivas de los corredores de seguros. En efecto, la Circular Básica Jurídica establece una sanción general al incumplimiento normativo, como la imposición de multas a la persona jurídica o individualmente a sus directivos o funcionarios ${ }^{\underline{62}}$. De otro lado, serán únicamente sometidas a control las agencias de seguros

59 OECD (2001) Policy Issues in Insurance Insurance Regulation, Liberalisation and Financial Convergence, OECD Publishing, 27 mai 2001, Paris, pag. 10.

60 La Rota, M. E., Lalinde, S., \& Uprimny, R. (2013). Análisis general y comparativo de tres poblaciones, Encuesta Nacional de Necesidades jurídicas, Dejusticia, recuperado el 20/08/2018.

61 Numeral 1.4 en el Capítulo II Titulo IV de la Parte Segunda de la Circular Basica Juridica.

62 Régimen Sancionatorio Administrativo de la Superintendencia Financiera de Colombia del Artículo 208 y ss del EOSF. 
que alcancen un tope determinado de comisiones ${ }^{63}$. Lo anterior significa que cuando los ingresos de la agencia no superen los topes establecidos en la ley, no hay mecanismo de supervisión del control delegado de los intermediarios personas naturales vinculadas, creándose un vació de regulación contrario al principio de inspección y control que debe guiar la existencia y funcionamiento de la Autoridad Prudencial y que a la postre puede permitir todo tipo de abusos en la venta de seguros.

\subsection{El control concentrado}

Más allá del rol que juegan las aseguradoras, se encuentra la disciplina contractual que rige las relaciones existentes entre los intermediarios de seguros y los usuarios. Dicha disciplina se encuentra establecida en un cuerpo normativo difuso ${ }^{64}$ que establece obligaciones directamente imputables a los distribuidores ${ }^{65}$ y que se concretan en el contenido contractual de forma implícita o explícita. Este control es concentrado por que el ejercicio de las autoridades jurisdiccionales se centra en sancionar los comportamientos contrarios a la disciplina contractual, es decir en disciplinar el comportamiento de los contratantes frente al contenido que debe regir el contrato según los principios de libertad, economía, equidad y distribución. Encontramos por ejemplo que se ordena que la información contenida en la póliza sea presentada en un formato específico $^{\frac{66}{}}$, con letras legibles y expidiendo al usuario copia del contrato $\frac{67}{}$, se prohíbe la presentación de un producto con características contrarias a la realidad, es decir mencionando garantías no contenidas en la póliza ${ }^{68}$, que se modifique el contrato sin informar al cliente, que se imponga la adquisición de otros servicios no pedidos o no necesitados, incluyendo los servicios ofrecidos ${ }^{69}$ por terceros o empresas asociadas ${ }^{70}$, que se renueven productos sin la autorización expresa del consumidor ${ }^{71}$, que se

63 Segun se establece en la Ley 964 de 2005 y manifestado en: Op. cit. Vivas Diez, G. J. (2014).

64 Es necesario aclarar que a pesar de la búsqueda en las bases de datos es posible que algunas normas hayan escapado de vista para la realización del presente estudio. Sin embargo nos remitimos al apuradísimo compendio realizado por un colega en esta misma revista en: Op. cit. Vivas Diez, G. J. (2014).

65 Aunque ellos nos son los únicos destinatarios puesto que gran numero de dichas obligaciones también son predicadas respecto de los aseguradores.

66 Art. 184 EOSF.

67 Circular 39 de 2011 de la Superintendencia Financiera, Numeral 10.3.

68 Ibid.

69 Circular 39 de 2011 de la Superintendencia Financiera.

70 Ley 1328 de 2009, Artículo 12.

71 Ibid. 
presuma la voluntad del consumidor ${ }^{72}$, restringiéndose específicamente considerar al silencio como un asentimiento a una obligación ${ }^{73}$ y que se cobre de manera automática los gastos de cobranza ${ }^{74}$. Se exige que se otorgue información clara, veraz, suficiente, oportuna, verificable, comprensible, precisa e idónea ${ }^{75}$, inhibiéndose en cualquier caso las estipulaciones contractuales que producen un desequilibrio injustificado ${ }^{76}$ en perjuicio de una de las partes, afectando su posibilidad de ejercer sus derechos ${ }^{77}$.

Cuando dichos postulados performativos son desconocidos por los intermediarios de seguros, el legislador les impone variadas sanciones: si es un desconocimiento de las obligaciones de información, el usuario puede sin penalidad alguna finalizar el contrato ${ }^{\frac{78}{4}}$; cuando se trata de cláusulas prohibidas, éstas se entienden no escritas $\frac{79}{0} \sin$ efectos $\underline{80}$ de pleno derecho ${ }^{\frac{81}{}}$; cuando se trata del no cumplimiento de los requisitos exigidos respecto del contrato ${ }^{\frac{82}{}}$, se sanciona con nulidad ${ }^{\frac{83}{3}}$, con la prohibición de la utilización de la póliza o incluso con la suspensión del certificado de autorización de ejercicio ${ }^{84}$, además de la imposición de multas o la destitución a los directivos o funcionarios implicados en los actos falentes $\frac{85}{}$. De manera general se puede decir que cualquier comportamiento reprochable es objeto del procedimiento sancionatorio de competencia de la Superintendencia Financiera ${ }^{\frac{86}{6}}$.

\footnotetext{
72 Circular 39 de 2011 de la Superintendencia Financiera, 10.3.

73 Ley 1480 de 2011, Art. 50.

74 Circular 39 de 2011 de la Superintendencia Financiera, 10.3.

75 Ley 1480 de 2011, Art. 3.

76 Este criterio ha sido implementado en otras jurisdicciones, luego de complicadísimas discusiones, lo que lleva a manifestar que por lo menos en este aspecto la regulación nacional sigue la vanguardia internacional del equilibrio contractual, a pesar de que en otros países europeos dicha sanción no está solo limitada a los contratos de consumo, sino que hace parte de los principios generales de los códigos de obligaciones y contratos.

77 Ley 1480 de 2011, Art.42.

78 Ley 1328 de 2009, Art. 10.

79 Ley 1328 de 2009, Art. 11.

80 EOSF Art. 184.

81 Ley 1480 de 2011, Art.42.

82 O de sus condiciones generales: Ley 1328 de 2009, Art. 37.

83 Ley 1480 de 2011, Art.44.

84 Pero en este caso la nulidad o ineficacia de una cláusula no afectará la totalidad del contrato, en la medida en que éste pueda subsistir sin las cláusulas nulas o ineficaces, EOSF Art. 184.

85 Como autoriza la Superintendencia en caso de incumplimiento de exigencias legales, Estatuto Organiso Sistema Financiero, Art. 184.

Op. cit. Vivas Diez, G. J. (2014).
} 


\subsection{El control sustantivo}

Paralelo a los dos anteriores mencionados medios de control, los operadores jurisdiccionales han desarrollado autónomamente una supervisión del comportamiento profesional de los intermediarios de seguros a través de la declaración de la responsabilidad civil con fundamento en la violación de normas sustanciales que se concretan en la violación de bienes jurídicos y/o la verificación de perjuicios. Al respecto es necesario mencionar que la particularidad de la intermediación de seguros es que, debido a que los deberes del tomador dentro del contrato de seguros son cumplidos a través / con la colaboración del intermediario, éste puede verse envuelto en situaciones de complicidad (explícita o implícita) con el tomador en la realización de faltas contractuales. En tal caso, la responsabilidad existirá cuando la reticencia tuvo lugar por una insinuación del intermediario que aconsejó falentemente el tomador. Pero en el caso del mandato con representación, el consejo profesional defectuoso es imputable al asegurador, situación que no impedirá una indemnización (aunque parcial) del asegurado, pues en tal caso, como ha sido afirmado en otras jurisdicciones, la culpa del tomador se diluye en aquella del asegurador ${ }^{87}$. Esta dilución de culpas no tiene lugar cuando el asegurador no se reputa como conocedor de los riesgos que su intermediario conocía. Así, si el intermediario no había recibido un mandato de suscripción, se considera que el único con poder de aceptar los riesgos y analizar la existencia de una reticencia era el asegurador y en tal caso la ficción de la representación deja de ser legítima ${ }^{88}$.

La creación de riesgos injustificados, por parte del profesional de la intermediación, implica la atribución de la responsabilidad civil cuando dicho comportamiento falente se concreta en situaciones de perjuicio del tomador-asegurado por la violación de las obligaciones de información como la ley colombiana lo establece ${ }^{89}$. En tal caso, la exoneración del intermediario no puede tener lugar sino a través de la prueba de la fuerza mayor o del hecho de que la información fue adulterada o suplantada sin que se hubiera podido evitar la adulteración o suplantación. ${ }^{90}$.Al respecto es necesario mencionar que el legislador colombiano sigue la

87 Op. cit. Mayaux, L. (2000).

88 Ibid.

89 Ley 1480 de 2011, Art.24.

90 Ley 1480 de 2011, Art.24 e igualmente mencionado en: Op. cit. Vivas Diez, G. J. (2014). 
teoría de la imputación objetiva ${ }^{91}$ para predicar la responsabilidad de los profesionales en el campo de seguros, puesto que la sola falta a los imperativos reglamentarios no constituye el titulo jurídico de imputación de responsabilidad civil cuando ésta no está acompañada de la prueba de la existencia de los perjuicios causados con dicho comportamiento, situación que ha sido validada por la doctrina nacional ${ }^{92}$. Pero esta situación tiene que ser replanteada en Colombia respecto de las situaciones en las cuales la responsabilidad penal ha sido verificada por la autoridad competente, más allá de los mecanismos de constitución de parte civil en dicha jurisdicción ${ }^{93}$, o cuando un perjuicio consistente en la pérdida de oportunidad de encontrar una mejor asesoría o un mejor contrato en el mercado es verificado por las autoridades jurisdiccionales.

\subsection{La reforma en concreto}

La intervención estatal que limita el la libertad contractual y las libertades económicas tiene su justificación en el hecho de que la actividad aseguradora, integrante del ámbito financiero, debe ser regulada para proteger a los usuarios y asegurar la libre competencia entre los actores dentro del modelo colombiano de economía social de mercado ${ }^{94}$. Independientemente que, por circunstancias retoricas pasajeras o de falta de formación en ésta área técnica, los tribunales hayan considerado que la actividad de intermediación no es de orden público en ausencia del manejo de recursos captados del público, supuesto que es totalmente falso ${ }^{95}$. Pero más allá de ello, el control estatal de la actividad de intermediación se justifica por el hecho de que los seguros en sí mismos son ampliamente regulados por el legislador, a pesar de que es una actividad típicamente de la esfera privada de los individuos. En efecto, existiría una paradoja si se buscara controlas

91 Sobre el particular la obra de referencia por el Profesor Ochoa Bernate, F. (2010) Imputación objetiva y responsabilidad penal médica, Universidad del Rosario, Bogotá, 2010.

92 « No existe una norma que obligue al juez a seguir o fallar en el mismo sentido de la decisión que haya tomado el organismo de vigilancia y control... Podría llegar a implicar indemnización de perjuicios por el incumplimiento de las obligaciones profesionales a su cargo, previa demanda y decisión judicial en tal sentido » en : Op. cit. Vivas Diez, G. J. (2014).

93 El principio de prevalencia de la responsabilidad penal sobre el civil es aplicado en jurisdicciones europeas, por ejemplo Francia y Suiza: Labbée, P. (1995) Introduction au droit processuel, Presses Univ. Septentrion, 1995.

94 Como es entendida por la Corte Constitucional, por ejemplo en la Sentencia C263 de 2011.

95 "aunque orgánicamente hablando la ley considere que ellos en ciertos casos forman parte de la estructura del sistema financiero, desde un punto de vista funcional, dichos intermediarios no pueden considerarse instituciones financieras o aseguradoras, por cuanto no manejan, no aprovechan, ni invierten dineros captados del público" en Corte Constitucional Sentencia C- 479 de 1999, reiterada por C-384 de 2000 y C-079 de 2011. 
la actividad desarrollada por las empresas de seguros sin que a su vez se regule la actividad de los intermediarios ${ }^{96}$, intervinientes esenciales de la actividad aseguradora. Además de ello, la complejidad de la actividad de aseguramiento y la necesidad de protección de la parte débil de la relación justifica la intervención estatal en esta área.

Buscando superar un vacío normativo ${ }^{97}$, la Superintendencia Financiera, en ejercicio de sus competencias regulatorias expidió el 28 de diciembre del 2015, expidió la Circular Externa 050 de 2015 buscando regular los estándares de idoneidad aplicables a las personas que ejercen la intermediación de seguros, las obligaciones de información propias al sector, la publicidad y transparencia propias a la intermediación de seguros, además de proporcionar medidas de gobierno corporativo asociado a estas materias. Para presentar estas reformas mencionaremos en primera medida cuales son los requisitos de ejercicio que en adelante son exigidos a los profesionales y futuros profesionales de ésta área(2.2.1) para luego especificar cuáles son las medidas tendientes a proteger los clientes (2.2.2).

\subsubsection{Requisitos de ejercicio}

El legislador establece unos requisitos de ejercicio referidos a la competencia técnica y a la idoneidad que deben cumplir los distribuidores de seguros. Esta intervención estatal se debe a que, por un lado, las faltas de conocimiento y profesionalismo inciden en el ejercicio de los derechos de los tomadores-asegurados. En efecto, un intermediario que olvida u omite transmitir oportunamente al asegurador una proposición o una solicitud de modificación del contrato solicitada por el asegurado o incluso una declaración de siniestro, puede implicar, por no decir que en la mayoría de los casos implica, una pérdida de los derechos del usuario ${ }^{98}$. Pero de otro lado, la falta de verificación de la competencia del intermediario genera una violación directa de las normas que regulan el sector, específicamente aquellas establecidas por las autoridades prudenciales y los gremios profesionales ${ }^{99}$. De esta forma, presentaremos en primera medida los requisitos de competencia técnica (2.2.1.1) y luego referirnos a aquellos de idoneidad (2.2.1.1).

96 Delamare-Deboutteville, C. E. et al. Lamyline (204) Lamy Assurances, Intermédiaires d'assurance, Partie 4, Chapitre 1, N4620.

97 Fajardo, L. (2016) La idoneidad de los intermediarios de seguros, Asuntos Legales, La Republica, 11 de abril de 2016, recuperado el 20/08/2018.

98 Op. cit. Mayaux, L. (2000).

99 Ibid. 


\subsubsection{Competencia técnica}

El hecho de que los requisitos necesarios para ejercer la intermediación fueran establecidos unilateralmente por las compañías de seguro creaba un riesgo de falta de rigurosidad en la escogencia del personal $\frac{100}{}$, con las consecuencias ya mencionadas. Se entendió entonces que era necesario reglamentar el oficio y formalizar la profesionalización de la intermediación en seguros.

El legislador colombiano había exigido el cumplimiento del requisito de tener conocimientos suficientes sobre la actividad de intermediación de seguros o reaseguros, según unos criterios de acreditación y validación $\frac{101}{}$. Actualmente, la Reforma vino a establecer que los corredores de seguros deben velar por que las personas naturales vinculadas a éstos cumplan con los requisitos de capacidad técnica ${ }^{102}$. Por ello se impone que los corredores de seguros establezcan métodos para controlar la capacidad profesional de manera previa a la vinculación o al momento de efectuar la actualización de su capacidad técnica ${ }^{103}$. Respecto de la acreditación de experiencia ${ }^{104}$, aquellas personas que durante al menos dos (2) años hayan desempeñado funciones de dirección o administración en entidades del sector asegurador; o prestado asesorías relacionadas con la intermediación de seguros; o desempeñado funciones relacionadas con el objeto social de las aseguradoras, pueden hacer valer dicha experiencia para efectos de la acreditación de su capacidad técnica. Dicha experiencia debe ser demostrada y documentada por la persona natural vinculada y comprobada por el corredor de seguros ${ }^{105}$. No obstante lo anterior, estas personas estarán sujetas al deber de efectuar un curso de actualización ${ }^{106}$.

Pero estas reglas de control no se encuentran únicamente establecidas respecto de los Corredores de Seguros. La Reforma estableció la obligación de las empresas aseguradoras de velar por que las personas naturales vinculadas a la misma aseguradora, a las agencias de seguros o a los agentes de seguros, cumplan con los requisitos de capacidad técnica para el ejercicio de las funcio-

\footnotetext{
100 Op. cit. Clavijo, L. (2015).

101 Art. 2.30.1.1.3 Decreto 2555 de 2010.

102 Numeral 1.4.1.1.4 Capitulo III, Titulo IV, Parte 2 Circular Basica Juridica.

103 Numeral 1.4.1.1.4 Capitulo III, Titulo IV, Parte 2 Circular Basica Juridica.

104 En línea con lo establecido en el artículo 2.30.1.1.3 del Decreto 2555 de 2010.

105 Numeral 1.4.1.1.4 Capitulo III, Titulo IV, Parte 2 Circular Basica Juridica.

106 Numeral 1.4.1.1.4 Capitulo III, Titulo IV, Parte 2 Circular Basica Juridica.
} 
nes de intermediación en seguros ${ }^{107}$. Para tal efecto, las personas naturales que ejerzan la intermediación de seguros deben contar con una capacidad técnica validada por la empresa de seguros, de manera que sea acreditado que estos intermediarios tienen los conocimientos mínimos necesarios para desarrollar dicha actividad ${ }^{108}$. Estas características técnicas se refieren a los conocimientos mínimos necesarios para la intermediación en los ramos autorizados y a que dichos conocimientos se actualicen periódicamente. Así, de manera paralela a los operadores intermediarios de los corredores de seguros, las personas naturales vinculadas a las aseguradoras, agencias y agentes de seguros, deben cumplir con los requisitos de capacidad técnica a través de la realización de un curso de actualización y de exámenes de conocimiento, como mínimo cada 4 años. Por ello se debe excluir la posibilidad de otorgar/renovar la autorización a personas que han demostrado con su comportamiento una ausencia de reiterada de capacidad técnica para ejercer la intermediación en seguros. La acreditación de capacidad técnica es también reglamentada para el sector de riesgos laborales y es aplicable a los agentes de seguros, a los representantes legales y a las personas naturales que laboran para los corredores de seguros y las agencias de seguros en dicho ramo ${ }^{109}$.

\subsubsection{Idoneidad}

La Reforma les impuso a los corredores de seguros y a las empresas aseguradoras la obligación concreta de verificar que las agencias de seguros y los agentes de seguros cumplan con los requisitos de idoneidad necesaria para la intermediación en los ramos autorizados a éstas ${ }^{110}$.

Es un objetivo principal del legislador delegado el garantizar que las personas morales vigilen que las personas naturales que éstos vinculan ejerzan sus funciones de acuerdo con dichas sanas prácticas comerciales, financieras y de seguros. Para tal efecto, la Reforma impone a los Corredores de Seguros la creación de mecanismos para corroborar la idoneidad de dichas personas naturales que ejercen la intermediación en seguros en beneficio de dichas entidades ${ }^{111}$. Así, el Corredor de Seguros debe cerciorarse debe expedir un Código de ética y de conducta donde se establezcan las sanciones consistentes en dar

107 Numeral 7.2.1 Capitulo II, Titulo IV, Parte 2 Circular Basica Juridica.

108 Numeral 7.2.1 y 7.2.2 Capitulo II, Titulo IV, Parte 2 Circular Basica Juridica.

109 Ley 1562 de 2012 y Decreto 1637 de 2013.

110 Numeral 1.4 de su Parte Segunda, Titulo IV, Capitulo III y Numeral 7.2.1 Capitulo II, Titulo IV, Parte 2 Circular Basica Juridica.

111 Numeral 1.4 de su Parte Segunda, Titulo IV, Capitulo III Circular Basica Juridica. 
por terminada la vinculación de la persona infractora, así como la publicidad de dicha sanción en el Sistema Unificado de Consulta de Intermediarios de Seguros, SUCIS.

En cualquier caso, las entidades aseguradoras deben velar por que las personas naturales vinculadas ejerzan la intermediación de seguros de acuerdo con las sanas prácticas comerciales, financieras y de seguros $\frac{112}{\text {, }}$

Por ultimo debemos mencionar que la probidad está íntimamente ligada a la idoneidad en el sentido de que la perdida de la confianza social sobre el sector asegurador es catastrófica para el tráfico económico que se verá privado de las ventajas de protección que solo el sector asegurador puede aportar. Así, la falta de idoneidad de un intermediario puede ser imputable directamente a la compañía, puesto que el asegurador será responsable de los fondos ilegalmente apropiados por un intermediario cuando el intermediario tenía autorización de percepción de primas o en el caso del mandato aparente ${ }^{113}$. Pero si el autor de la apropiación ilegal es un intermediario con facultad de representación de la empresa aseguradora, ésta será de pleno derecho responsable de las pérdidas sufridas por los clientes que confiaron en la persona por ella designada, responsabilidad que se predica sin consideración a las defensas basadas en la exoneración a la responsabilidad por el hecho ajeno, régimen que no corresponde a un esquema como el del asegurador-intermediario-asegurado, regido por la responsabilidad contractual $\frac{114}{4}$. Para evitar estos inconvenientes la probidad tiene que ser vinculada con la idoneidad y así las sanciones que se apliquen en el ámbito financiero a los intermediarios o las infracciones de carácter penal (en sentido amplio), deben tener repercusión sobre la posibilidad de ejercicio de las personas condenadas y sancionadas de manera que no sean admitidas a practicar la intermediación en seguros $\frac{115}{}$.

\subsubsection{Protección de los usuarios}

Los análisis económico y jurídico del contrato de seguro coinciden en que éste tiene implícito un riesgo moral que requiere la aplicación

112 Numeral 7.2.2 Capitulo II, Titulo IV, Parte 2 Circular Basica Juridica.

113 Op. cit. Mayaux, L. (2000).

114 Ibid.

115 Si una inhabilidad definitiva es mas deseable, los constitucionalistas exigiran un lapso de inhabilidad subsiguiente a la sancion/condena, lapso que debe entonces ser en este sentido establecido por el legislador. 
de un imperativo de buena fe extrema ubirreamae fidei, es decir una exigencia de lealtad imperiosa de los contratantes ${ }^{116}$. Es precisamente este punto el que lo distingue de los otros contratos y que lleva a algunos a afirmar que la aplicación del régimen de protección del consumidor tiene que ser restringido para el área de seguros $\frac{117}{}$. Nosotros pensamos sin embargo que la protección del usuario, independientemente de si su origen es lego o profesional, es uno de los pilares sobre los cuales ha reposado la regulación del contrato de seguro y no es por otra razón que la practica ha simplemente enseñado en varios siglos de uso de este mecanismo contractual que las decisiones del asegurador deben ser objeto de control jurisdiccional. De igual manera se considera que la legislación de protección al consumidor debe ser aplicable a todos los sectores de la economía, específicamente respecto de los contratos de seguro, así como en los contratos preparatorios del mismo. El derecho constitucional admite esta extensión de garantías en el derecho de la intermediación en seguros, a través de los principios de intervención estatal financiera y de protección de toda persona, natural o jurídica, no perteneciente al sector del producto vendido $\frac{118}{}$. Es por ello que las reformas de la intermediación de seguros a ambos lados del océano Atlántico se han centrado en la imposición al intermediario de seguros de deberes de información de doble textura, autónomas y compartidas $\frac{119}{11}$. Así, en lo que a Colombia respecta, dicha doble protección se reflejó en la Reforma a través de la imposición de deberes de información (2.2.2.1 y 2.2.2.2) además de la prevención de los conflictos de interés (2.2.2.3).

\subsubsection{La protección a través de la información}

La Reforma, siguiendo la tendencia contemporánea en los países de tradición occidental, ha impuesto unas obligaciones de información, que son expresadas en unos mandatos de asesoría y redacción de documentos, avance esperable de la regulación colombiana, al introducir principios de textura abierta, específicamente la información debida por el intermediario de $\operatorname{seguros} \frac{120}{}$. Si el acreedor al que le son impuestas tales obligaciones de

116 Op. cit. Mayaux, L. (2000).

117 Ibid.

118 Corte Constitucional, Sentencia C-909 de 2012.

119 Citando el Concepto jurídico No. 076084, Diciembre 07 de 2011 de la Superintendencia Financiera, un autor menciona que las obligaciones de información de las aseguradoras son aplicables a los intermediarios de seguros, en: Op. cit. Vivas Diez, G. J. (2014).

120 Salgado, P. J. (2012). La protección del consumidor de seguros en Colombia: antecedentes, evolución, retos y perspectivas. Revista Ibero-Latinoamericana de Seguros, 21(37), Bogota. 
información está plenamente identificado, esto es el tomador-asegurado o los terceros adherentes en los seguros colectivos, la identificación de quién es el deudor genera usualmente más inconvenientes, pues se está en presencia de un número plural de intervinientes en la cadena de distribución ${ }^{121}$. El asegurador tiene un deber autónomo de expedir documentos contractuales de información y de asesoría al usuario ${ }^{122}$, pero dicha obligación no exime en modo alguno aquella que le es propia al intermediario de seguros que está supeditado a unas cargas generalmente predicables a todo actor del sistema financiero, así como también está sometido a otras cargas específicas de los distribuidores de contratos de seguros. Más aún, estas obligaciones de información del intermediario no se predican únicamente respecto del tomador-asegurado, sino igualmente respecto del asegurador que debe recibir a su vez la información transmitida por el usuario $\frac{123124}{\text {, }}$ circunstancia que frente a los corredores de seguros está expresamente indicada en la ley, concretamente en relación con toda información que en alguna forma pueda influir en la celebración del negocio, en beneficio de ambas partes, asegurador y asegurado $\frac{125}{}$.

El legislador colombiano ha querido que toda entidad financiera otorgue información suficiente y oportuna, antes de concluir el contrato y de forma permanente en su sitio web $\frac{126}{}$, ofreciendo una copia del mismo $\frac{127}{\text {, }}$ redactado en castellano y sin espacios en blanco $\frac{128}{2}$, permitiendo al usuario conocer oportunamente $\frac{129}{2}$ sus derechos y obligaciones $\frac{130}{}$, así como la forma de ejercer los mecanismos de protección $\frac{131}{2}$, pero además individualizando el precio de cada producto o servicio $\frac{132}{2}$.

121 Op. cit. Mayaux, L. (2000).

122 Lo cual en el derecho nacional ha sido tradicionalmente relacionado con la obligación del asegurador de depositar las diferentes versiones de los contratos de seguro ante la Superintendencia Financiera, articulo 1047 del Código de Comercio. Sobre el particular ver: Ordóñez, A. E. O. (2005). Deberes Reciprocos de Informacion en el Contrato de Seguro y Especialmente el Deber de Informacion del Asegurador Frente al Tomador del Seguro, Los. Revista de Derecho Privado, 9, 75, Bogota.

123 Corredores de Seguros, Concepto 2002044968-1 del 11 de septiembre de 2002 Superintendencia Financiera de Colombia, Información al cliente, responsabilidad por incumplimiento de este deber. Sanciones administrativas. Responsabilidad civil por daños y perjuicios.

124 Nótese que esta disposición cumple con los parámetros establecidos en la ley 1328 de 2009, referente a la revelación del monto del valor de los servicios prestados por la entidad vigilada.

125 Código de Comercio, art. 1344.

126 Circular 38 de 2011 de la Superintendencia Financiera de Colombia.

127 Ley 1328 de 2009, Título I y más particularmente el artículo $9^{\circ}$.

128 Ley 1480 , Art.37

129 Ley 1328 de 2009, artículo 3 lit c).

130 Ley 1328 de 2009, Art. 9.

131 Ley 1480 de 2011, art. 3 y la Ley 472 de 1998; Art. 4 Lit. n.

132 Ley 1480 de 2011 articulos $5^{\circ}$ y 24 , y la Ley 1328 de 2009 articulo $9^{\circ}$. 
Más particularmente, se impone, de un lado, precisar los amparos y exclusiones en el contrato ${ }^{133}$ de una manera perfectamente legible ${ }^{134} \mathrm{en}$ un clausulado entregado tanto previamente ${ }^{135}$ como posteriormente ${ }^{136} \mathrm{al}$ tomador-asegurado, el valor del servicio de intermediación ${ }^{137} y$ de los deducibles, los periodos de carencia y de permanencia, los requisitos de edad, la posibilidad de renovación automática y/o unilateral, toda circunstancia tendiente a limitar el derecho a obtener una indemnización, como los plazos y formas de la declaración del siniestro, la posibilidad de devolución de primas, la advertencia de las consecuencias de la reticencia, además de los recursos en caso de rechazo de cobertura ${ }^{138}$. De otro lado, el legislador también enlistó los comportamientos expresamente reprochables, como el expedir notas de cobertura que no identifican las normas aplicables, que pertenecen a otras entidades o que no reproducen el texto de la póliza, utilizar formatos que no han sido verificados por la Superintendencia, u otorgar información inexacta sobre esos formatos ${ }^{139}$.

Todo lo anterior con el objetivo de permitir al usuario de escoger las mejores opciones del mercado ${ }^{\frac{140}{}}$ puesto que se presume de la entrega de documentos al usuario, el respeto de la obligación de información y de esta manera se satisface al imperativo constitucional de autonomía de la voluntad y al principio de derecho civil de libertad contractual $l^{141}$.

\subsubsection{El contenido de la obligación de información}

En Colombia, el otorgamiento de información se establece como una obligación de las entidades integrantes del sistema financiero, obligación cuyo contenido se predica principalmente en las etapas precontractuales, sin que se agote en éstas pues las partes (y en especial la entidad de seguros) deben proveer información al usuario lo largo de todo el contrato, así como el usuario está obligado a informar al asegurador toda circunstancia que tienda a modificar su percepción del riesgo.

133 Ley 1480 artículo 37.

134 Numeral 1.2.1.2. Capitulo III, Título IV, Parte 2, Circular Básica Jurídica.

135 Ley 1480, Art.37.

136 Específicamente en los seguros colectivos: Decreto 673 de 2014 Artículo 2.36.2.2.8.

137 Decreto 673 de 2014 Artículo 2.36.2.2.8.

138 Circular 38 de 2011 de la Superintendencia Financiera de Colombia

139 Numeral 1.7 Capitulo II Titulo IV, Parte 2 de la Circular Básica Jurídica.

140 Artículo $9^{\circ}$ Ley 1328 de 2009.

141 Pero aun así es discutible créer que en un país como el nuestro la mera entrega de documentos genere consciencia en el asegurado de todas las particularidades de este contrato especial que es el seguro. 
La Reforma a la Intermediación en Seguros en Colombia consolida ${ }^{142}$ estas obligaciones de información, cuya vigencia comienza el 1 de diciembre de 2018. Se ordena que la información que suministren las entidades vigiladas a través de terceros (asesores, agentes comerciales, entre otros) deba ser concordante con aquella contenida en los contratos correspondientes y con la divulgada o publicitada por la entidad a través de los diferentes medios y/o canales; además de que tiene que ajustarse a la realidad jurídica y económica del servicio promovido ${ }^{143}$. Pero más allá de los lineamientos generales mencionados más arriba, la Reforma impuso ${ }^{144}$ unos deberes específicos para las personas naturales vinculadas que ejercen como intermediarios, para que previamente a la celebración del contrato de seguro se provean la siguiente información de manera cierta, suficiente, clara y oportuna: los derechos y obligaciones emanados del contrato de seguro, el alcance de la cobertura, de las exclusiones y de las garantías, el procedimiento para la reclamación de un siniestro, la lista de sus distribuidores y los canales para formular una petición, queja o reclamo $\frac{145}{}$.

2.2.2.3. Prevención de los conflictos de intereses a través de la información

La jurisprudencia se ha interesado al tipo de relación existente entre el intermediario de seguro y la compañía aseguradora principalmente para efectos de establecer un nexo de causalidad entre un acto falente del primero y el rol jugado por el segundo respecto del cliente asegurado. Sin embargo, dicha relación profesional y mercantil no debe tener únicamente importancia para el derecho legislado y pretoriano respecto de la posible existencia de una solidad y/o representación entre el intermediario y la compañía, sino además frente a la manera en la cual se ejerce el comercio de seguros. En efecto, el mercado solo cumple su efecto democratizador y de impulso del rendimiento económico si los actores tienen suficiente información para tomar decisiones racionales. Es por ello que la relación existente entre intermediario y compañía importa al derecho, puesto que un posible conflicto de intereses puede perturbar la eficiencia del mercado y falsear las opciones de acceso al sistema financiero que tiene un

142 Numeral $3^{\circ}$ de la Parte Primera, Titulo III, Capitulo I de la Circular Basica Juridica.

143 Numeral 3.2.3.3. de la Parte Primera, Titulo III, Capitulo I de la Circular Basica Juridica.

144 Numeral 3.4.3.1 de la Parte Primera, Titulo III, Capitulo I de la Circular Basica Juridica.

145 Numeral 3.4.3.2.11. de la Parte Primera, Titulo III, Capitulo I de la Circular Basica Juridica. 
cliente determinado. El Estado debe entonces intervenir y regular esta relación, no necesariamente para crear un nuevo título de imputación de responsabilidad civil, sino para prevenir comportamientos que afectan el funcionamiento del mercado y entraben el acceso al servicio.

Por ello, independientemente de la existencia de obligaciones de información autónomas, una interpretación que toma a todos los intervinientes en la cadena de distribución como deudores de la obligación de información, de la misma manera que lo son los vendedores sucesivos de una misma cosa (obligados a proveer una garantía del bien objeto del contrato), es aprobada y deseable, puesto que es más protectora del asegurado $\frac{146}{y}$ del desarrollo económico. En efecto, si uno de los eslabones de la cadena de distribución desaparece, por ejemplo cuando el potencial cliente prefiere omitir contactara a su agente de seguros para dirigirse directamente al asegurador, el respeto de las obligaciones de información tiene que ser en tal garantizado directamente por el asegurador $\frac{147}{}$.

La doctrina tiende a diferenciar los riesgos que se concentran en la intermediación de seguros estableciendo una distinción entre los consejos interesados y los consejos de conveniencia $\frac{148}{}$. En los primeros, el intermediario tiene un interés directo en los consejos que él otorga ${ }^{149}$, o peor aún, tiene un interés directo en dar un mal consejo ${ }^{150}$ entorpeciendo el funcionamiento económico de los actores. Así, el intermediario remunerado a través de comisiones adjuntas a las primas $\frac{151}{5}$, puede verse tentado ${ }^{152}$ a maximizar sus ventas ${ }^{153}$ y a subir precios $\frac{154}{}$ pues entre más alta la prima, mayor será la remuneración ${ }^{155}$, haciendo suscribir a los clientes contratos que no son adaptados o que son inútiles respecto de las necesidades expresadas por el usuario. El consejo interesado también

146 Op. cit. Mayaux, L. (2000).

147 Ibid.

148 Ibid.

149 Es el caso del agente de seguros sometido al pacto de exclusividad que implica que su capacidad de análisis del mercado está legalmente limitada.

150 Op. cit. Mayaux, L. (2000).

151 Ibid.

152 Este riesgo es particularmente evidente respecto del corredor facultado para recaudar la prima, Concepto No. 1998045982-2, Octubre 23 de 1998, Superintendencia Bancaria.

153 Es el caso del agente que puede tener tendencia a proponer un contrato que le aporta un mayor margen de remuneración, a pesar de que en consideración de las necesidades del cliente, el amparo que debió habersele ofrecido era otro, en una aseguradora diferente a la propuesta.

154 Mora, C. et Zarruk, A. (2010) Bancaseguros en la distribución de productos de vida, Revista Fasecolda, Bogota.

155 Op. cit. Bermúdez, D. (2013). 
genera conflicto de interés respecto de los agentes subordinados bajo un contrato de trabajo $\mathrm{u}$ otra forma laboral asimilable, los cuales pueden ver su imparcialidad comprometida si la empresa de seguros para la cual trabajan les impone metas de venta excesivas, concentradas sobre cierto tipo de productos. El conflicto de interés tiene lugar respecto de las agencias en los casos en que el asegurador impone unos márgenes de venta para acceder a otros beneficios o comisiones $\frac{156}{}$. En tales casos, la agencia se puede ver obligada a vender más de un producto en perjuicio de otro que sería más adecuado para la necesidad de cobertura expresada por el cliente. Este tipo de consejo interesado es falente desde el punto de vista jurídico aunque no necesariamente desde el comercial y tiene lugar más particularmente en todos los casos en los que el intermediario representa los intereses de una parte, pero su remuneración es asumida por otra $\frac{157}{\text {, }}$ lo cual puede manifiestamente perturbar su capacidad de realizar un análisis imparcial del mercado de seguros, turbando subsiguientemente la asesoría que otorga al cliente en sus necesidades de protección. Es por ello que en algunos códigos deontológicos se establece que la tasa de remuneración del intermediario no debe en ningún caso influenciar la calidad del servicio ${ }^{158}$.

De otro lado, el consejo de conveniencia $\frac{159}{15}$ es aquel en el cual el intermediario asesora a un cliente en el sentido de aconsejarle realizar una declaración de riesgos reticente o incluso de sobrevalorar sus pérdidas en caso de siniestro, con el solo objetivo de obtener una prima menos elevada o de enervar las consecuencias negativas del juego de la regla proporcional de capitales $\frac{160}{}$. Otra situación en la cual se puede ver reflejada este tipo de inconvenientes deontológicos se encuentra en la comisión contingente ${ }^{\frac{161}{6}}$ por resultado técnico de cuenta. En ésta, el intermediario recibe comisiones de remuneración inversamente proporcionales con el comportamiento de la cuenta en términos de siniestralidad, situación que puede generar conflictos de interés por parte del intermediario, como lo menciona la doctrina $\frac{162}{2}$. Si bien esta clasificación del riesgo moral del intermediario se puede apli156 Ibid.

157 Ibid.

158 France, Code Moral des Courtiers, citado por: Op. cit. Mayaux, L. (2000).

159 Me distancio del Profesor Mayaux que les llama «Conseil d'amitié ». Por el elemento de colusión propio a éste conflicto de interés yo prefiero denominarlos « de conveniencia » ver: Op. cit. Mayaux, L. (2000).

160 Op. cit. Mayaux, L. (2000).

161 Vargas Mancera, M. J. (2009) Comisiones a intermediarios en Colombia, Revista Fasecolda nro 131, Bogota.

162 Op. cit. Bermúdez, D. (2013). 
car en casos en los cuales el intermediario utilizaba papel membretado de la aseguradora, o expedía en su nombre certificados de cobertura, o incluso aceptaba o rechazaba solicitudes de rescisión del contrato, ella es inconsecuente para los casos en que la apariencia de la representación era inexistente y las circunstancias del acto debió haber creado en el usuario una semilla de duda 163 .

Son todos éstos los riesgos de consejos interesados o de conveniencia que el derecho busca limitar creando las obligaciones de información de los intermediarios de seguros. No queda duda de que la responsabilidad civil tiene posibilidades restringidas para imponer comportamientos en los actores cuando los montos o bienes jurídicos en juego no son de magnitud suficiente para atribuir obligaciones indemnizatorias, y por ello se considera que imponer de forma general obligaciones de información en cabeza de los profesionales de la venta de seguros disminuye las posibilidades que tienen tales personas de cometer fraude o de dejar que sus clientes lo hagan, al mismo tiempo que se busca proteger la mutualidad financiera creada con los contratos de seguro, y por el mismo camino, se protege el asegurador, puesto que las advertencias previas proporcionadas por el intermediario van a disuadir los actos fraudulentos provenientes del concurso del asegurado y el intermediario. Esta esperada consecuencia tiene lugar cuando por ejemplo, el intermediario que estando obligado a informar al usuario sobre las consecuencias de las inexactitudes respecto de la cobertura, provee dicha información al cliente, y éste, consciente de los problemas que trae la deshonestidad, toma la decisión de no participar en una situación de colusión orquestada por el distribuidor del seguro.

El derecho colombiano impone unas obligaciones de información referidas específicamente a la prevención de los conflictos de interés. De este modo, el intermediario está obligado a informar el precio en pesos colombianos, incluidos todos los impuestos y costos adicionales de los productos ${ }^{164}$, como son los generados por los estudios de crédito, seguros, transportes o cualquier otra erogación $\frac{165}{}$. Más aun, se exige que en los casos de disputa entre los beneficios del operador y los de los consumidores, siempre prevalezca el interés de éstos últimos ${ }^{166}$, circunstancia que es considerada por la doctrina como uno de los principios rectores del 163 Op. cit. Mayaux, L. (2000).

164 Ley 1328 DE 2009, articulo 9.

165 Ley 1480 articulo 26.

166 Ley 1328 de 1992 articulo $3^{\circ}$ lit e). 
sistema financiero colombiano $\frac{167}{}$. El control normativo de los conflictos de interés lo vemos en el área específica de riesgos laborales, puesto que el intermediario que actúa ante el mismo empleador no podrá recibir remuneración adicional de la administradora de riesgos laborales, por la prestación de servicios asistenciales o preventivos de salud ocupacional $\frac{168}{}$, además de que la administradora de riesgos laborales que recurra a un intermediario, deberá sufragar su remuneración con cargo a sus recursos propios ${ }^{169}$. Lo vemos también en el caso del uso de las redes de oficinas de terceros por parte intermediarios de seguros, en el cual se exige que se adopten las medidas necesarias para que el público identifique claramente al intermediario como una persona distinta y diferente del establecimiento de crédito o la empresa a la cual pertenecen esas oficinas $\frac{170}{}$. La aspiración del legislador es que al proveer tal información, se permita y facilite al usuario la adecuada comparación de las distintas opciones ofrecidas en el mercado $\frac{171}{}$, sabiendo con ello la extensión del análisis al cual puede aspirar con un intermediario determinado y los riesgos que pueden surgir respecto del rol de éste en el servicio de seguro.

Pero más especialmente, con la Reforma de la Intermediación introducida por la Superintendencia Financiera de Colombia en 2015 y de aplicación definitiva en diciembre de 2018, se ambicionó controlar los conflictos de interés exigiendo que las personas naturales que son vinculadas para la distribución de productos de seguro, suministren al consumidor información sobre: el alcance de los servicios de intermediación, los costos del producto y su comercialización, la forma de vinculación contractual del intermediario con la entidad aseguradora y su estado de inscripción en el registro, la responsabilidad que como intermediario le corresponde frente al consumidor financiero, además de la autorización otorgada por la entidad aseguradora $\frac{172}{}$. Más aún, la Reforma identificó las personas, responsables directos, del respeto de las obligaciones de información a cargo de los intermediarios de seguros. Así, se estableció ${ }^{173} q u e$ corresponde a la junta directiva de los corredores de seguros instaurar las

167 Op. cit. Vivas Diez, G. J. (2014).

168 Decreto 1637 de 2013, Artículo 3 y la Ley 1562 de 2012. Más aun, segun el Artículo 81 del Decreto 1295 de 1994, en ningún caso la A. R. P. sufragará el monto de honorarios o comisiones cuando la intermediación sea contratada por el empleador para la selección de la A. R. P.

169 Ley 1562 de 2012, Art. 11.

170 EOSF Artículo 93.

171 Ley 1328 DE 2009, articulo 9.

172 Capítulo I, Título III, Parte I de la Circular Basica Juridica, numeral 3.4.3.

173 Numeral 1.4.2. del Capítulo III, Título IV, Parte II de la Circular Basica Juridica. 
políticas necesarias para garantizar el cumplimiento de los requisitos de idoneidad de las personas naturales vinculadas a sus empresas, que ejerzan labores de intermediación de seguros y el cumplimiento del deber de información por parte de los éstos. A parte de estas personas, se instituyó una obligación de información general (no vinculada al ofrecimiento y la conclusión de un contrato de seguro) a todos los actores que deben en adelante informar en sus páginas web los cargos que se generan por la utilización de los servicios de la compañía, los conceptos que se incluyen en la prima y los pagos adicionales por aspectos no contemplados de manera específica ${ }^{174}$. Igualmente se prohíbe formalmente el cobrar por servicios no prestados o por prestaciones propias del contrato que no implican ningún servicio adicional 175 .

Otras formas de control existen en Colombia, diferentes a aquellos en que se exige el otorgar información. Principalmente, la distinción legal entre los agentes dependientes e independientes puede dar una idea de en qué medida es imparcial el análisis del mercado realizado por un in-

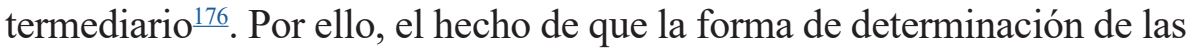
comisiones y formas de pago esté enmarcada por ley y sea reflejada en el contrato de distribución $\frac{177}{17}$, permite realizar controles fiscales, judiciales y sociales sobre dichos montos, y más particularmente por los clientes por medio de una solicitud expresa en este sentido.

\section{CONCLUSIONES}

La Reforma de la intermediación en seguros introducida en Colombia sigue en gran parte los elementos principales de aquella implementada en Europa. Sin embargo nuestra legislación se quedó corta en algunos aspectos que se deben mencionar, veamos:

- Una diferencia existe entre la definición dada a la intermediación en ambas reformas. Mientras que la Reforma europea definió la intermediación a través de los verbos adaptación, redacción y celebración del con-

174 Numeral 3.4.3.2.8 Capítulo I, Título III, Parte I de la Circular Basica Juridica.

175 Circular 39 de 2011 de la Superintendencia Financiera, Numeral 10.2.

176 Estatuto Orgánico del Sistema Financiero, Numerales 1, 5 y 6 art. 41.

177 Decreto 2605 de 1993, Artículo 4 y Decreto 2555 de 2010, Art. 2.30.1.1.4. 
trato, la Reforma colombiana se limitó a definirla con los verbos asesoría, acompañamiento y adquisición. El hecho de intervenir en la conclusión del contrato es un elemento común a ambas definiciones, la asesoría y acompañamiento de la reforma colombiana hace pensar que para el legislador colombiano el eje central del servicio está en el proceso de retroalimentación que se realiza con el intermediario a través de lo que es narrado por el usuario. Empero, la adaptación y redacción a que hace referencia la reforma europea, nos hace pensar que para el legislador continental el eje del servicio se centra en las labores de consecución y ajuste del contrato. De este modo, mientras que en Colombia se espera del intermediario una labor acentuada de suministrar consejos, en la Unión Europea se espera es una labor de concretar dichos consejos en documentos contractuales. Por ello, mientras en Colombia se piensa la intermediación como un servicio, en la Unión Europea se concibe como un producto tangible y palpable, esto es el documento contractual de cuya claridad depende la existencia del producto. Nos limitaremos a decir que el control judicial y social del comportamiento del intermediario en seguros es más fácilmente llevado a cabo a través de un documento, situación que es la contraria en ausencia de dicha prueba pues el usuario se verá abocado a demostrar un hecho negativo de la parte adversa, lo cual a la postre exigirá al intermediario aportar la prueba de que se otorgó la información y en ausencia de un documento esta prueba es difícil consecución.

- Contrario a lo que afirman las aseguradoras $\frac{178}{}$, el control delegado es obsoleto para garantizar que en el país no se están vulnerando masivamente los derechos de los usuarios del servicio de intermediación en seguros. Por ello, como se afirma en el numeral §II.2.B.iii) del presente estudio, para cumplir con los objetivos del OCDE, Colombia debe reorientar su manera de controlar los intermediarios de seguros, más allá de si son vigilados o si tienen o no facultad de representación, pues estos son criterios que complican más el esquema de inspección y terminan permitiendo que deshonestos operadores busquen diluir su responsabilidad en el caótico ambiente procesal colombiano, mientras que las victimas pierden sus recursos y la sociedad en general es despojada de la credibilidad necesaria del sistema financiero y judicial.

178 (2015)Las aseguradoras responden a cuestionamientos del Congreso, Revista Dinero 9/2/2015, recuperado el 20/08/2018. 
- En Colombia, son únicamente sometidas a control las agencias de seguros que alcancen un tope determinado de comisiones $\frac{179}{}$. Así, con ingresos inferiores a los topes establecidos en la ley, el intermediario escapa a los mecanismos de supervisión del control delegado, creándose un vació de regulación contrario al principio de inspección y control que debe guiar la existencia y funcionamiento de la Autoridad Prudencial y que a la postre puede permitir todo tipo de abusos en la venta de seguros.

- La ley colombiana no estableció un sistema de autorización de funcionamiento, únicamente un sistema de registro (SUCIS) que no es controlado por nadie y no sirve de referencia alguna, y en comparación con los avances propios de este sector en todas las jurisdicciones de los países occidentales $\frac{180}{}$, solo nos queda por decir que la ausencia de control directo por la autoridad prudencial es tan absurda como simplemente concluir que el legislador colombiano no desatiende con ello todos los riesgos que surgen de la captación y manipulación de recursos por parte de los intermediarios de seguros.

- El mejoramiento de la regulación en seguros debe ser un objetivo principal del legislador $\frac{181}{2}$, sin duda alguna, pero en un país como el nuestro en el que actores particulares se inventan ingeniosas maneras de violentar sus obligaciones o incluso de sustraer recursos $\frac{182}{2}$ a través de maniobras fraudulentas, es necesario establecer medidas de control más drásticas como las encontradas en todos los países industrializados, esto es, la (i) obligación de contratación de seguros para todas las empresas de seguros e intermediarios, solo limitado en los casos de existencia de una cautiva, (ii) la constitución de una garantía financiera, monto establecido por el legislador y dejado como depósito en beneficio de los intereses en juego, más allá de las protecciones propias que se dan desde el derecho

179 Segun se establece en la Ley 964 de 2005 y manifestado en: Op. cit. Vivas Diez, G. J. (2014).

180 «In any case, the authorisation or the license, for individuals or entities that intend carrying out intermediation activities on a primary basis, is beyond any doubt a common element whichever jurisdiction is taken into consideration » : Graber, C. Pucci, (2015) E. IBA Insurance Intermediation, 2015 Report, Insurance Committee Substantive Project 2015

181 Pero es además un gran reto que "genera oportunidades de crecimiento importantes para las aseguradoras, pero también riesgos, los cuales deben ser vistos y analizados a partir de su integralidad": Mejía Aramburo, Sebastián (2017) La desintermediación en el contrato de seguro. De la bancaseguros al uso de red, 46 Rev.Ibero-Latinoam.Seguros, 109-148

182 Este riesgo es particularmente grave cuando el intermediario esta habilitado para recibir primas, como lo menciona la doctrina respecto del riesgo moral: Op. cit. Bermúdez, D. (2013). 
de sociedades y finalmente (iii) siguiendo los mandatos del OCDE $\frac{183}{}$, el establecimiento de un régimen propio y particular de insolvencia para estas entidades $\frac{184}{}$, para evitar que los fondos se esfumen como ha ocurrido en otros casos colombianos de descalabros financieros.

- Respecto de los conflictos de interés, si bien la Reforma buscó que todas las personas naturales vinculadas estuvieran obligadas a otorgar información sobre los costos del servicio y la remuneración, la redacción actual de la Circular (CBJ) puede dar pie a una interpretación restrictiva, excluyendo a las personas jurídicas diferentes a la aseguradora misma. Por ello, hasta que este punto sea precisado por una Alta Corte o por el legislador, los operadores jurídicos deben apoyarse sin limitación alguna en el objetivo de la norma que no es otro que enervar los conflictos de interés que pueden surgir de la intermediación en seguros.

- Otro aspecto en el cual la regulación colombiana es falente es respecto a la evaluación de necesidades de cobertura del cliente. En efecto, en la Unión Europea se exige que el intermediario justifique la escogencia del contrato que ofrece al cliente a través de un documento estandarizado de necesidades de cobertura, en el cual se debe consignar que es lo que el cliente solicita, que es lo que en realidad necesita y porqué se le ofrece un producto determinado. Este documento sería de gran uso para el país y debería ser objeto de regulación por el legislador porque de nada sirve que se imponga a los intermediarios de seguro tener en cuenta la solicitud y necesidades del cliente, pero de otro lado dicha obligación no se concretice en un documento contractual objeto de posibles controles. Si hay profesionales que lidian con bienes jurídicos mucho más riesgosos, como la vida y la salud, están obligados a la redacción de largos documentos, no vemos porque tales obligaciones no deberían igualmente ser impuestas a intermediarios de seguros que no lidian sino con los bienes económicos de las personas.

- Por último, si bien un régimen de inhabilidades se establece respecto de las entidades vigiladas por la Superintendencia Financiera, nada se estableció en la Reforma sobre las inhabilidades propias a los interme-

183 OECD (2002) Insurance Solvency Supervision Country Profiles: OECD Country Profiles, OECD Publishing, 3 avr. 2002, pag 49 Paris.

184 Viñals and S. Lizondo (2013), Colombia Financial System Stability, Monetary and Capital Markets and Western Hemisphere Departments, International Monetary Fund, January 9, 2013 
diarios de seguros. Es de vital importancia imponer barreras de acceso a la profesión de intermediación a las personas que han incurrido en sanciones disciplinarias o cometido delitos contra los bienes ajenos. Un ejemplo de ello es que en la Unión Europea ninguna persona que haya cometido delitos en contra del sistema financiero, contra las sociedades comerciales, contra la honradez y la rectitud propias al manejo de recursos ajenos, puede ejercer la intermediación en seguros $\frac{185}{\text {. }}$.

\section{BIBLIOGRAFÍA}

\section{Libros y revistas}

Bérmudez, D. (2013), El rol del intermediario de seguros en La industria aseguradora en Colombia, Avances en el siglo XXI, Fasecolda, Bogotá.

Clavijo, L. (2015, septiembre 15). La intermediación de seguros en Colombia debe ser profesionalizada. Revista Fasecolda, 160, 36-39, recuperado el 20/08/2018.

Delamare-Deboutteville, C. E. et al. Lamyline (204) Lamy Assurances, Intermédiaires d'assurance, Partie 4, Chapitre 1, $\mathrm{N}^{\circ} 4620$.

Fajardo, L. (2016) La idoneidad de los intermediarios de seguros, Asuntos Legales, La Republica, 11 de abril de 2016, recuperado el 20/08/2018.

Fasecolda (2018) Los costos de la intermediación en Colombia ascendieron a un 15\% solo para mayo de 2018, Fasecolda, Cifras mayo 2018, Bogota.

Gil, M. V. G. (2013). El derecho occidental del siglo XXI y el concepto de familia jurídica. Revista de derecho: División de Ciencias Jurídicas de la Universidad del Norte, (39), 30-57.

Graber, C. Pucci, (2015) E. IBA Insurance Intermediation, 2015 Report, Insurance Committee Substantive Project 2015

185 Consideracion Nro 30, Directiva (Ue) 2016/97 del Parlamento Europeo y del Consejo de 20 de enero de 2016 sobre la distribución de seguros. 
Jonathan Bloch, Laury André (2015) La Réforme protestante, de Luther à Calvin: La réponse aux abus de la religion catholique, 50 minutes, Paris.

Labbée, P. (1995) Introduction au droit processuel, Presses Univ. Septentrion, 1995.

La Rota, M. E., Lalinde, S., \& Uprimny, R. (2013). Análisis general y comparativo de tres poblaciones, Encuesta Nacional de Necesidades jurídicas, Dejusticia, recuperado el 20/08/2018.

Luc Mayaux Ethique et offre d'assurance, Revue générale du droit des assurances, 01/04/2000, n² 2000-2, Lextenso, RGDA2000453.

Mejía Aramburo, Sebastián (2017) La desintermediación en el contrato de seguro. De la bancaseguros al uso de red, 46 Rev.Ibero-Latinoam. Seguros, 109-148

Meneses Paternina, J. (2014) El Nuevo rol del intermediario de seguros, $2^{\circ}$ Congreso Internacional de Seguros: Actuales paradigmas jurídicos, Fasecolda, Santa Marta Mayo de 2014, recuperado el 20/08/2018.

Montealegre Escobar, J. O. (2016) Futuro de la Intermediación de Seguros en Colombia, 3 Congreso Internacional de Derecho de Seguros, Fasecolda, Pereira, mayo 5 de 2016, recuperado el 20/08/2018.

Mora, C. et Zarruk, A. (2010) Bancaseguros en la distribución de productos de vida, Revista Fasecolda, Bogota.

Ochoa Bernate, F. (2010) Imputación objetiva y responsabilidad penal médica, Universidad del Rosario, Bogotá, 2010.

OECD (2001) Policy Issues in Insurance Insurance Regulation, Liberalisation and Financial Convergence, OECD Publishing, 27 mai 2001, Paris, pag. 10.

OECD (2002) Insurance Solvency Supervision Country Profiles: OECD Country Profiles, OECD Publishing, 3 avr. 2002, pag 49 Paris. 
OECD (2011) Insurance Regulation and Supervision in Asia and Latin America, 11 juin 2001, OECD Publishing, Paris, Pag. 92.

Ordóñez, A. E. O. (2005). Deberes Reciprocos de Informacion en el Contrato de Seguro y Especialmente el Deber de Informacion del Asegurador Frente al Tomador del Seguro, Los. Revista de Derecho Privado, 9, 75, Bogota.

Salgado, P. J. (2012). La protección del consumidor de seguros en Colombia: antecedentes, evolución, retos y perspectivas. Revista Ibero-Latinoamericana de Seguros, 21(37), Bogota.

Simiele, Javier. (2010). Lutero y la política. Enfoques, 22(1), 71-90. Recuperado en 16 de agosto de 2018.

Tabares Cortés, F. (2017). La reforma del Código Civil Francés. Un proemio al cambio estructural de los principios de derecho privado del Código Napoleónico. Revista Verba Luris, (38), 155-169.

Tascón Ortiz, J. B. (2015) La responsabilidad civil de los intermediarios de seguros, UPB Tesis de Grado Repository, Universidad Pontificia Bolivariana, Bogota.

Vargas Mancera, M. J. (2009) Comisiones a intermediarios en Colombia, Revista Fasecolda nro 131, Bogota.

Viñals and S. Lizondo (2013), Colombia Financial System Stability, Monetary and Capital Markets and Western Hemisphere Departments, International Monetary Fund, January 9, 2013

Vivas Diez, G. J. (2014) Transparencia en los contratos de seguros: Cláusulas e información precontractual, Revista Ibero-Latinoamericana de Seguros, RIS, Bogotá, Universidad Javeriana, 41(23): 39-80.

(2015) Las aseguradoras responden a cuestionamientos del Congreso, Revista Dinero 9/2/2015, recuperado el 20/08/2018.

(2015) El debate que tendrán que enfrentar las aseguradoras. El representante a la Cámara David Barguil anunció control político para corre- 
gir algunas prácticas en las empresas aseguradoras y le dio un tirón de orejas a la regulación de seguros. Revista Dinero 9/4/2015, recuperado el 20/08/2018.

Normas, documentos legislativos y sentencias

Directiva (UE) 2016/97 del Parlamento Europeo y del Consejo de 20 de enero de 2016 sobre la distribución de seguros.

Avis du Comité économique et social européen sur 1 «Proposition de directive du Parlement européen et du Conseil sur l'intermédiation en assurance (refonte)» COM (2012) 360 final, 2012/0175 (COD) 2013/C 44/16 Rapporteure: Mme Ellen Nygren.

Propuesta de Directiva Del Parlamento Europeo y del Consejo sobre la intermediación en los seguros COM/2012/0360 final - 2012/0175 (COD) */52012PC0360

Directiva 2002/92/CE del Parlamento Europeo y del Consejo, de 9 de diciembre de 2002, sobre la mediación en los seguros (DO L 9 de 15.1.2003, p. 3).

2.2.2016 ES Diario Oficial de la Unión Europea L 26/19, Por el Parlamento Europeo, el Presidente M. Schulz, por el Consejo el Presidente, A.G. Koenders.

Sentencia C263 de 2011 Corte Constitucional de Colombia.

Sentencia C- 479 de 1999, Corte Constitucional de Colombia.

Sentencia C-384 de 2000 Corte Constitucional de Colombia.

Sentencia C-079 de 2011 Corte Constitucional de Colombia.

Corte Suprema de Justicia, Sala Civil, 26 de junio de 2018, SC3426-2018.

Conceptos Superintendencias 
Concepto 2016132848-001 del 11 de enero de 2017 Superintendencia Financiera de Colombia Captación Masiva y Habitual y Actividad Aseguradora Ilegal, Prevención.

Concepto No. 1998045982-2, Octubre 23 de 1998, Superintendencia Bancaria.

Corredores de Seguros, Concepto 2002044968-1 del 11 de septiembre de 2002 Superintendencia Financiera de Colombia, Información al cliente, responsabilidad por incumplimiento de este deber. Sanciones administrativas. Responsabilidad civil por daños y perjuicios.

Concepto $N^{\circ}$ 1998045982-2. Octubre 23 de 1998, Superintendencia Financiera de Colombia, Primas, Responsabilidad en su Recaudo por Corredores de Seguros. 